\title{
Chapter 7 \\ Mesoscale Modelling of the Arctic \\ Atmospheric Boundary Layer and Its Interaction with Sea Ice
}

Christof Lüpkes, Timo Vihma, Gerit Birnbaum, Silke Dierer,

Thomas Garbrecht, Vladimir M. Gryanik, Micha Gryschka, Jörg Hartmann,

Thomas Garbrecht, Vladimir M. Gryan, Siegfried Raasch, Hannu Savijärvi,

K. Heinke Schlünzen, and Ulrike Wacker

Abstract This chapter summarises mesoscale modelling studies, which were carried out during the ACSYS decade until 2005. They were aiming at the paramcocesses in the Arctic boundary layer over the open ocean and marginal sea ice zones and over the Greenland ice sheet. It is of fluxes in It is shown that progress has convection over leads. strong convective situations such as cold-air outbreaks and convection over leads. A first step was made towards the parameterization of the lead-induced turbulence
for high-resolution, but non-eddy resolving models. Progress has also been made

C. Lüpkes $($ 四 $) \bullet$ G. Birnbaum $・$ V.M. Gryanik $・$ J. Hartmann $\bullet U$. Wacker

Alfred Wegener Institute for Polar and Marine Research, Postfach 120161, D-27515

Bremerhaven, Germany

e-mail: christof.luepkes@awi.de; gerit.birnbaum@awi.de; vladimir.gryanik@awi.de

jorg.hartmann@awi.de; ulrike.wacker@awi.de

T. Vihma

Finnish Meteorological Institute, POB 503, FIN-00101 Helsinki, Finland

e-mail: timo.vihma@fmi.fi

S. Dierer $\bullet$ K. H. Schlünzen

.

Bundesstr. 55, D-20146 Hamburg, Germany

e-mail: sdierer@web.de; heinke.schluenzen@zmaw.de

T. Garbrecht

OPTIMARE Sensorsysteme GmbH \& Co. KG, Am Luneort 15a, D-27572

Bremerhaven, Germany

e-mail: thomas.garbrecht@optimare.de

M. Gryschka • S. Raasch

Institute of Meteorology and Climatology, Leibniz University of Hannover,

D-30419 Hannover, Germany

e-mil: rryschk@@mukuni-hannover.de; raasch@muk.uni-hannover.de 
with the parameterization of the near-surface atmospheric fluxes of energy and momentum modified by sea ice pressure ridges and by ice floe edges. Other studies brought new insight into the complex processes influencing sea ice transport and atmospheric stability over sea ice. Improved understanding was obtained on the cloud effects on the snow/ice surface temperature and further on the near-surface turbulen fluxes. Finally, open questions are addressed, which remained after the ACSYS decade for future programmes having been started in the years after 2005.

Keywords Polar atmospheric boundary layer - Atmosphere-ice-ocean interaction - Sea ice $\bullet$ Leads $\bullet$ Cold-air outbreaks $\bullet$ Surface roughness

\subsection{Introduction}

The Arctic atmospheric boundary layer (ABL) exhibits several characteristics, which have a large influence on the transport processes of mass, energy and momentum and their exchange between the atmospheric, oceanic and cryospheric parts of the Arctic climate system. The spatial scale of these processes is mostly smalle than that resolved by large-scale climate models. So, the application of mesoscale models can help to obtain a better understanding and quantification of the processes and to develop and test their parameterization for models using different grid sizes. Examples of characteristic features of the Arctic ABL, which need further consideration with respect to (climate-) modelling and parameterization and which have been addressed during ACSYS, are the following:

The first one concerns the ABL thickness. Over the huge pack-ice region, it is mostly below $400 \mathrm{~m}$. But during off-ice flow regimes with cold-air outbreaks, the height increases over the open ocean with increasing distance from the ice edge to values of sometimes more than $2,000 \mathrm{~m}$ in a distance of several $10 \mathrm{~km}$ off the ice edge.

The second peculiarity of the Arctic ABL concerns its stratification. According to radiosonde sounding data from Russian ice stations, surface-based inversions prevail during winter. They extend to a height of approximately $1,200 \mathrm{~m}$, with a

\section{G. Heinemann}

Department of Environmental Meteorology, University Trier, D-54286 Trier, Germany e-mail: heinemann@uni-trier.de

L. Kaleschke

Institute of Oceanography, University of Hamburg, Bundesstr. 55,

D-20146, Hamburg, Germany

e-mail: lars.kaleschke@zmaw.de

H. Savijärvi

Department of Physics, University of Helsinki, P.O. Box 64, 00014, Helsinki, Finland e-mail: hannu.sarvijarvi@helsinki.fi

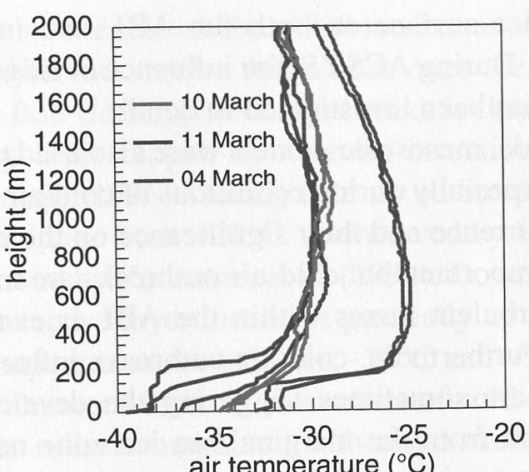

air temperature $\left({ }^{\circ} \mathrm{C}\right)$

7.1 Temperature profiles north of the Fram Strait marginal sea ice zone during cold Fig. conditions in March 1993, measured during the campaign REFener Institute

typical temperature increase of 10-12K (Serreze et al. 1992b). Ship and aircraft data from the Atlantic sector of the Arctic Ocean show that in winter and early spring, especially during low temperatures around $-30^{\circ} \mathrm{C}$, strong surface-based spring, especially during low temperatures ares the inversions inversions can exist also in this region. But at higher temperatures, the inversions 100-250 m thickness (Fig. 7.1). Modelling studies presented in this section are mostly bable or near-neutral mostly based on the latter condition prevails in the ABL over sea ice with a capping inversion of variable thickness and temperature increase.

The stable stratification over sea ice is caused by various reasons. These are the generally negative radiation balance over snow and ice and, during on-ice flow regimes, also the advection of warm air from the open ocean over the cold ice surface (e.g. Overland and Guest 1991). The performance of models for these situations was not well known before the ACSYS decade.

A third peculiarity of the Arctic ABL is caused by the inhomogeneities in the ice A A tribution ranging from large transitional zones between the open ocean and pack ice (marginal ice zones) to regions in the pack ice with open water patches and/or in thin-ice areas (leads and polynyas). Leads exist during the whole year even in regions with thick pack ice. Due to divergent sea ice drift, leads are formed with lengths of up to hundreds of kilometres extending over the Arctic. Over leads, strong lengths of up to hundreds of kilomen when they are covered with thin ice. These convective plumes can develop even when they are cover with gravity waves plumes penetrate into the stably stratified ABL while generating gravity waves (Mauritsen et al. 2005). Due to the small width of leads, ABL processes in the vicinity of leads cannot be resolved by climate models, but have to be parameterized.

Both drift and deformation of sea ice depend on the vertical transport of momen-

Both drift and deformation of sea ice depengly influenced by the heterogeneous tum within the ABL. This transport is strongly influenced by the heterogeneous roughness of the sea ice surface due to inhomogeneous distribution of sea ice 
a heterogeneous sea ice surface on both the ABL and in turn on the drift and deformation of sea ice. During ACSYS, the influence of ridges and floe edges on the momentum transport has been investigated in detail.

In the ACSYS decade, mesoscale models were also used to study ABL processes over the open ocean, especially during conditions of cold-air outbreaks. Due to their high frequency of occurrence and their significance on the energy budget of ocean and atmosphere, it is important that cold-air outbreaks are investigated and that the parameterization of turbulent fluxes within the ABL is examined for this special type of flow regime. Furthermore, cold-air outbreaks influence huge regions over the Nordic Seas and are sometimes triggering the development of polar lows. Sometimes, they extend from the marginal sea ice zone near Svalbard far to the mid-latitudes while interacting with low-pressure systems over the Nordic Seas. Therefore, a correct treatment of cold-air outbreaks in models is of high relevance for air and ship traffic.

During ACSYS, also katabatic wind systems over the sloped ice sheet of Greenland have been modelled, which have a strong influence on the transport of momentum and energy and hence also on the mass balance of the ice sheet.

In this chapter, we give a review on mesoscale modelling studies of Arctic ABL processes during the ACSYS decade. Moreover, some case studies carried out during the ACSYS period are summarised, which are related to measuring campaigns (REFLEX, ARTIST, KABEG, WARPS).

Most of the modelling studies presented in this chapter have been carried out with the 2D hydrostatic mesoscale model UH of the University of Helsinki (Alestalo and Savijärvi 1985; Savijärvi and Matthews 2004; Vihma et al. 2005) and with the 3D non-hydrostatic mesoscale transport and fluid model METRAS developed at the University of Hamburg. METRAS is described by Schlünzen (1990) and Schlünzen et al. (1996) and a 2D version by Lüpkes and Schlünzen (1996).

\subsection{Cold-Air Outbreaks}

One of the most striking atmospheric phenomena in the Arctic is the formation of cold-air outbreaks with strong convection developing under off-ice wind conditions downstream of the pack-ice region. Satellite images document that between late autumn and early spring, this type of convection, visible by the typical cloud patterns, covers a large part of the Arctic ice-free ocean. Sometimes, cold-air outbreaks originating from the northern Fram Strait reach even to midlatitudes, and often, cold-air outbreaks interact with low-pressure systems over the Nordic Seas.

Cold-air outbreaks have been studied in much detail during the ACSYS decade by observations and mesoscale modelling. Several aircraft-based campaigns have been carried out over the northern Fram Strait (Brümmer et al. 1992; Brümmer 1997, 1999; Hartmann et al. 1992, 1999; Kottmeier et al. 1994) to investigate the boundary layer structure in a region of about $300 \mathrm{~km}$ extent around the marginal sea for observations, we know that over the Fram Strait pack-ice region, the atmospheric flow during cold-air outbreaks is characterised by a shallow slightly stable boundary layer capped by a strong inversion with a base at about 100-300 m height (Brümmer 1996). During cold-air outbreaks, the air temperatures north of the sea ice edge range from $-20^{\circ} \mathrm{C}$, as observed by Hartmann et al. (1992), down to $-35^{\circ} \mathrm{C}$, as observed by Kottmeier et al. (1994). Downstream of the ice edge, the thickness of the convective layer increases gradually up to values between 900 and $2.200 \mathrm{~m}$, and air temperatures are between $-15^{\circ} \mathrm{C}$ and $-5^{\circ} \mathrm{C}$ after $300 \mathrm{~km}$ fetch and 2,200 m, and air (Brümmer 1996). In most cases of cold-air outbreaks, the convection is organised into rolls accompanied with cloud streets and, at a distance of silometres downstream of the ice edge, into hexagonal cells (Etling and Brown 1993; Atkinson and Zhang 1996). In the last decade, numerous (Etling and Brown 1993; Atkinson and Zhang 1996). In the last decade, numerous studies of roll convection have been carried out with LES models (e.g. Chlond 1992; Raasch 1990; Hartmann et al. 1997; Müller et al. 1999; Gryschka and Raasch 2005; and many others). Liu et al (2004) presented the modeling of a cold air outbreak using a nonhydrostatic model with $500 \mathrm{~m}$ horizontal grid size and resolving the larger sized convection rolls. For shortness, we concentrate here, however, only on mesoscale modelling studies.

Due to the large differences between the temperatures of the open water surface and the near-surface air, extremely large heat fluxes with several $100 \mathrm{Wm}^{-2}$ occur over a very large region. Brümmer (1996) found from an analysis of ten cold-air outbreaks that the sensible and latent heat fluxes were the dominant terms in the outbreaks that the sensible and latent heat fluxes wered between 200 and $700 \mathrm{Wm}^{-2}$. In the pack ice, In contrast, the considerable amount of heat and moisture transported from the open ocean to the atmosphere and the related potential for the development of polar lows, it is impor atmosphe developmen of the convective ABL.

An accurate modelling of energy and momentum transport is especially difficult in the marginal sea ice zone. During cold-air outbreaks, the wind forcing on sea ice in thift tends to generate a diffuse ice edge with the ice concentration decreasing gradually over a long distance. Hence, during cold-air outbreaks, there is usually a significant heat flux from the open leads upstream of the ultimate ice edge. Parameterization of this subgrid-scale heat flux is one of the key aspects for a sucParamet during a cold-air outbreak (Vihma and cessful modelling of the ABL heat budget during a cold-air outoreak (Vinma and Brümmer 2002). Moreover, the high number of ice floe edges cause a large form drag, which has been found critical for an accurate parameterization of the surface drag, which hases (Birnbaum and Lüpkes 2002; Lüpkes and Birnbaum 2005). This momentum fluxes (Birnbaum and

In a time scale of hours, well-developed cold-air outbreaks are often quasithationary in the sense that the mixed-layer height and the mean fields of stationary in the sendity downstream of the ice edge change only slightly in temperature and humidity down strom herth and the strong heating from 

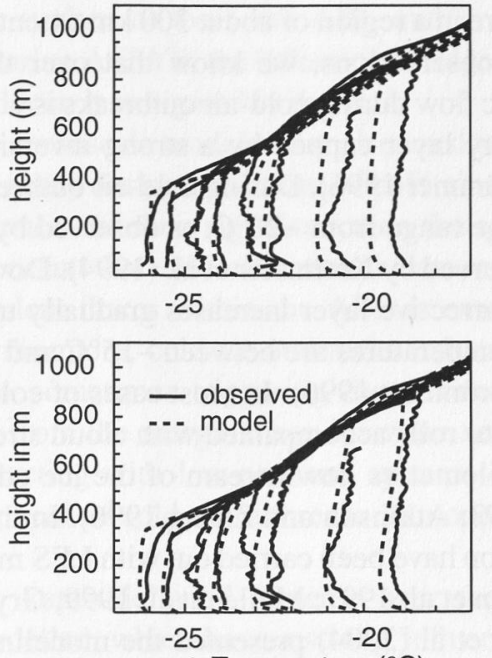

pot. Temperature $\left({ }^{\circ} \mathrm{C}\right)$

Fig. 7.2 Modelled and observed potential temperature during a cold-air outbreak, modelled without clouds $(t o p)$ and with clouds (bottom). The first three profiles on the left hand side are above the MIZ; the profile on the right end of the figure is $114 \mathrm{~km}$ downstream of the ice edge (From Augstein et al. 2000; a similar case is discussed in Kaleschke et al. 2001)

balance each other. This stationarity is the reason why cold-air outbreaks were considered during the ACSYS decade and already before for the testing and derivation of turbulence closures in 2D models. Lüpkes and Schlünzen (1996) tested several first-order closures. They used the non-hydrostatic model METRAS, which was initialised with observed profiles over pack ice and a geostrophic wind according to the observations. For a case of extreme convection observed during a cold-air outbreak by Kottmeier et al. (1994), it was shown that only schemes allowing very efficient turbulent mixing were able to reproduce the typical temperature structure of the well-mixed convective ABL. According to their study and a similar one by Chrobok et al. (1992), a strong mixing can be realised by closures allowing large eddy diffusivities with maxima in the order of several $100 \mathrm{~m}^{2} \mathrm{~s}^{-1}$. Furthermore, in a simple nonlocal closure as that of Troen and Mahrt (1986) or of Lüpkes and Schlünzen (1996), countergradient transport of heat and humidity contributes to the mixing.

The study of Lüpkes and Schlünzen (1996) was carried out with $4 \mathrm{~km}$ horizontal grid size. Nevertheless, their nonlocal closure can be used also with much larger grid sizes being typical for regional high-resolution climate or forecast models. As an example, results obtained from METRAS with $8 \mathrm{~km}$ horizontal grid size and with the nonlocal closure of Lüpkes and Schlünzen (1996) are shown in Fig. 7.2. It contains modelled and observed profiles of potential temperature for a cold-air outbreak on 5 April 1998 in the Fram Strait, which was studied during the campaign
Fig. 7.3 Modelled and observed heat fluxes referring to a cold-air outbreak, observed during the ARTIST campaign in the Fram Strait (From Augstein et al. 2000)

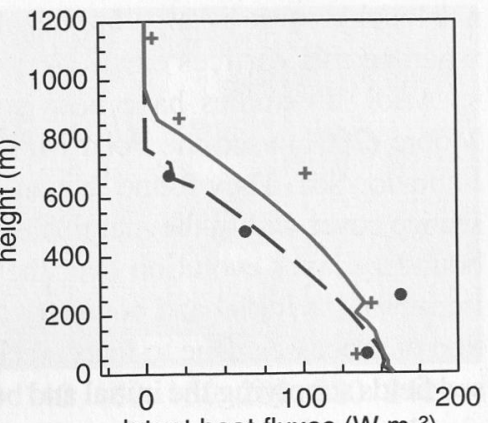

atent heat fluxes $\left(\mathrm{W} \mathrm{m}-2^{2}\right)$

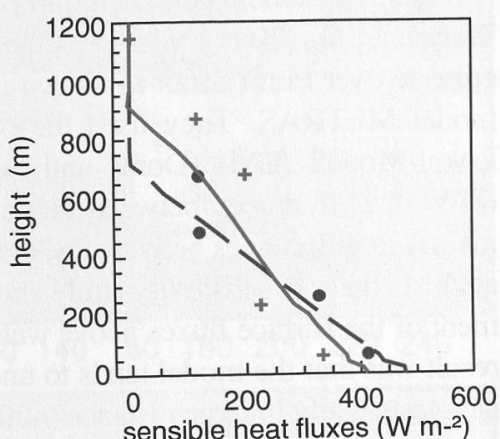

ARTIST (Hartmann et al. 1999). As described in detail by Kaleschke et al. (2001) he use of satellite-based sea ice concentration data in the marginal sea ice zone wa ( The important to obtain a good agreement between mofiles are smaller, when clouds are differences between modelled and observed profiles a accounted for (treated in this model run via the Kessler (1969) parameterization). A first glance, the agreement between modelled and observed fluxes of sensible and atent heat (Fig. 7.3) seems to be only fair; however, the error of the measurement is about $25 \%$ of the observed values, so there should not be too much emphasis on the differences.

Bearing in mind that the used closure of Lüpkes and Schlünzen (1996) does not consider explicitly any impact of roll vortices on the vertical transport of energy and momentum, the good quality of agreement between modelled and observed athers profiles as in Fo review article by Etling and Brown 1993), it (see Hartmann et al. 1997 and the review article by Etling and Browy. However, was found that roll vortices can contribute $25 \%$ to the transport of energy. However,
Fig. 7.2 proves that there exist at least cases where this additional effect of transport does not seem to play a large role. More case studies should be carried out in future to confirm this finding and to investigate whether any additional effect of

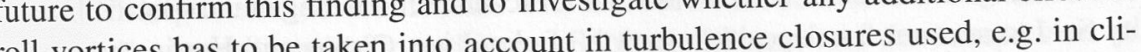
(2003) found that the above 
nonlocal closure is also applicable to cases with convection over land surfaces, when no roll vortices exist.

Also, 3D studies have been performed with mesoscale models. Pagowski and Moore (2001) used the Polar MM5 to model an extreme cold-air outbreak over the Labrador Sea. They found that an accurate representation of the inhomogeneities in sea ice cover within the marginal sea ice zone is necessary to reproduce the observed boundary layer evolution over the open sea. Furthermore, they point to the strong impact of the initial and boundary conditions in regional models used for the simulation of processes. Due to inaccuracies and to the limited resolution of the used analysed fields supplying the initial and boundary conditions, they were not able to correctly simulate the interaction of a cold-air outbreak with the formation of a polar low.

A similar conclusion on the importance of a high-quality analysis was drawn by Wacker et al. (2005), who presented 3D simulations of the same cold-air outbreak episode over Fram Strait as shown in Fig. 7.2 as a result from the 2D version of the model METRAS. They used the operational mesoscale weather prediction model Lokal-Modell (LM) (Doms and Schättler 2002) of the German Weather Service (DWD). Differences between model results and observations could be traced back mainly to differences between the observed ice conditions and those resulting from the analysis data. A sensitivity study showed that physical parameterizations as the treatment of the surface fluxes above water had a significant effect on the results. Another result was that the model tends to underestimate the convective boundary layer thickness, especially in large distance $(\sim 200 \mathrm{~km})$ from the ice edge. Since a similar problem occurred also in a simulation by Lüpkes and Schlünzen (1996), Wacker et al. (2005) speculated that in mesoscale models of this type, some physical processes, e.g. the penetration of plumes into the inversion layer, are not represented well enough. It can be expected that a similar problem would occur also in climate models unless mixing processes (entrainment) near the inversion are not explicitly parameterized.

The development of clouds during cold-air outbreaks was also addressed by Wacker et al. (2005). In contrast to the METRAS simulation discussed above, the cloud parameterization scheme includes also the ice phase. Wacker et al. (2005) could not find a significant influence of the ice phase on the evolution of the cold-air outbreak. Model runs with and without a consideration of ice particles in clouds resulted in only small differences, e.g. in the fields of temperature and cloud water content. Figure 7.4 contains a segment of the vertical north-south cross section along $5^{\circ} \mathrm{E}$ through the LM model domain, considered by Wacker et al. (2005). I covered an area of about $1,000 \times 1,500 \mathrm{~km}^{2}$ over the North Atlantic. According to the figure (not shown in Wacker et al. 2005), most of the condensate is in liquid form, although the temperatures are about $15-20 \mathrm{~K}$ below the freezing point. The maximum ice content is found close to the ice edge in cold air. Light precipitation falls out of the clouds. The amount of condensate, the dominance of liquid water, and presence of precipitation are in agreement with observations.

Also, Vihma and Brümmer (2002) considered the role of clouds during cold-air outbreaks. They found that it was essential for an accurate modelling of the specific humidity field to account for deposition growth of cloud ice. Olsson and Harrington (2000) conclude from their sensitivity study with a high-resolution 2D model that the amount of cloud condensate strongly influences the ABL structure due to radiation effects.
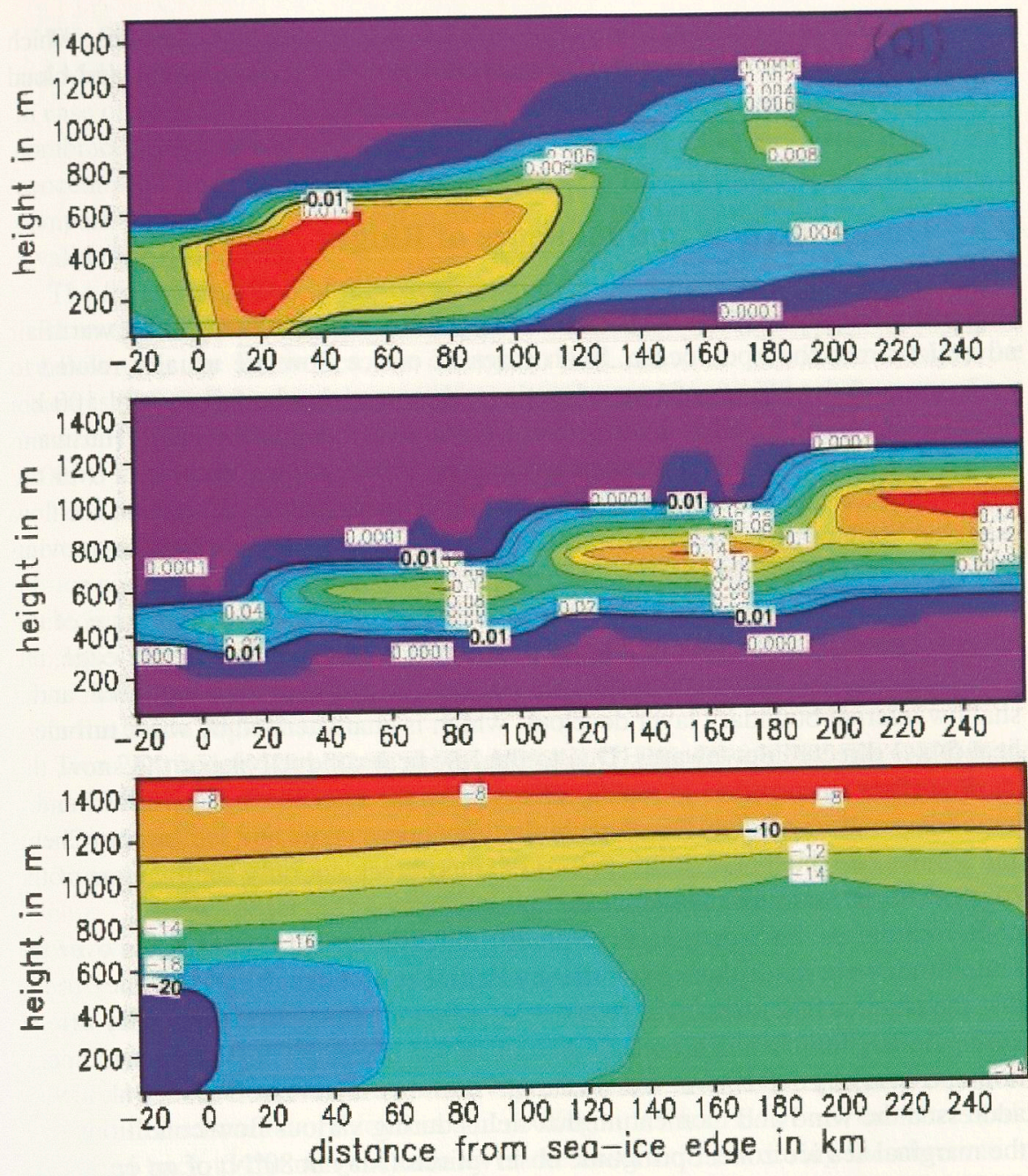

Fig. 7.4 Modelled potential temperature (bottom), liquid water content (middle) and ice conten 19. 7.4 Modelled potential (top) in g/kg during a cold-air outbreak obsert KVJ, Lüpes C, Hartmann J, Raschendorfer M Bottom Figure modified from Wacker U, Potty KVJ, Lupkes C, Hartann J, Raschendorfer M (2005) A case study on a polar cold air outbreak over Fram Strait using a mesoscale weather prediction model. Boundary-Layer Meteoro Springer Science+Business Media B.V.

\section{Summary and Conclusions}

In the ACSYS decade, several studies with mesoscale models have been carried out successfully to study cold-air outbreaks. Such model runs and the comparison of heir results with observations improved our understanding of the effect of different parameterizations on the development of the convective $\mathrm{ABL}$, and they helped to 
quantify the deficiencies of the model results. Remaining uncertainties, which should be subject to future research, concern the role of entrainment and cloud physical processes on the growth of the convective ABL.

\subsection{On-Ice Airflow and Influence of Ridges}

Especially in the marginal sea ice zone, the ABL is often influenced by warm-air advection from the open ocean. Such cases of on-ice flow are usually related to cyclones, and the effects of heat advection can sometimes be felt several $100 \mathrm{~km}$ downstream of the ice edge. During the springtime campaigns, ARTIST (Hartmann et al. 1999) and WARPS (Schauer and Kattner 2004) cold-air outbreaks over the Fram Strait were often accompanied by strong warm-air advection with on-ice flow over Storfjorden and the Barents Sea. This was due to low-pressure systems moving from southwest to northeast along the eastern side of Svalbard.

During on-ice flow, even in winter over the open ocean, the temperature of the advected air masses is close to the freezing point. While crossing the ice edge, the flow has to adjust to changed surface conditions: its properties are modified, and a shallow internal boundary layer develops, which is characterised by weak turbulent heat fluxes directed downwards. Due to the low heat conductivity of the snow, the snow surface temperature is rapidly affected by the overflowing warm air, and a large temperature gradient develops in the uppermost snow and ice layers (Cheng and Vihma 2002). Hence, on-ice flow is of importance not only for the state of the Arctic ABL but also for the sea ice thermodynamics.

Before the ACSYS decade, first aircraft observations of on-ice flows over the Fram Strait were made during summer by Fairall and Markson (1987). They found that the near-surface stress was reduced by a factor of two due to stability effects during on-ice flow. In at least one of their observed cases, the near-surface temperature decreased by $2.5 \mathrm{~K}$ over a distance of $70 \mathrm{~km}$. A review of Guest et al. (1995) addressed the wind and momentum flux fields during various flow conditions over the marginal sea ice zone. Springtime observations (May at $80^{\circ} \mathrm{N}$ ) of an on-ice airflow are presented by Brümmer et al. (1994). In their observations and in an aircraftbased study over the Baltic sea by Vihma and Brümmer (2002), the temperature differences between the air, ice and open sea were small, and so, the air-mass modification also remained small (a few tenths of a degree over horizontal distances of $100-300 \mathrm{~km}$ ). The next aircraft-based study was carried out by Brümmer and Thiemann (2002). They document a case with strong warm-air advection along a $300 \mathrm{~km}$ flight section from the Fram Strait MIZ north-west of Svalbard towards north-westerly direction across the pack ice. Over this distance, the internal ABL grew to a height of $145 \mathrm{~m}$, and the near-surface air temperature decreased from about $-2^{\circ} \mathrm{C}$ over the open ocean to about $-10^{\circ} \mathrm{C}$ at $100 \mathrm{~km}$ distance from the ice edge. The increase of $\mathrm{ABL}$ depth was not monotonic, but influenced by various factors such as cloud formation and inhomogeneous surface temperature. A strong temperature gradient of $12 \mathrm{~K}$ per $10 \mathrm{~km}$, related to a synoptic-scale front, was observed $270 \mathrm{~km}$ off the ice edge.
The first modelling study of on-ice flow was carried out before ACSYS by Kantha and Mellor (1989). They presented 2D simulations with different geostrophic wind. In case of on-ice flow, they described the development of a shallow boundary layer In case of on-ice flow, they described the development of a low-level jet. An analogous modelling study by Glendening (1994) concentrated mainly on ice-parallel flow regimes. Neither study included a comparison with data since sparse data existing at that time could not be used for a validation of models.

The first comparison of mesoscale model results with aircraft data on the spatial ABL variability was made by Vihma and Brümmer (2002), but in their case of onice flow over the Baltic Sea, the change in ABL structure was dominated by the changes in surface roughness and temperature at the coastline. A comparison between model results and data of on-ice flow was carried out by Vihma et al (2003). This study is explained in the remaining part of this section in more detail.

As a part of the campaign ARTIST (Hartmann et al. 1999), aircraft observations were carried out in spring 1998 over the Storfjord (Svalbard) during conditions of on-ice airflow. Low-level flights were performed at about $30 \mathrm{~m}$ height, and standard meteorological parameters, turbulent fluxes and sea ice topography were measured, the latter with a laser altimeter along a distance of about $150 \mathrm{~km}$ along the mean wind. Due to the on-ice flow regime, the sea ice concentration was close to $100 \%$ over the entire flight distance.

Two 2D models were used: the hydrostatic UH model and the non-hydrostatic model METRAS. Both were initialised at the inflow boundary over water with the observed profiles of temperature and humidity. Based on observations, the same oberved pronies of the model runs with a horizontal grid size of $2 \mathrm{~km}$ Figure 7.5 shows observed and modelled profiles of wind and temperature along the Figure 7.5 shows observed and modelled profiles of wind and temperature a of about $50 \mathrm{~km}$ width with thin pancake ice, and on its southern end, the first profile was $50 \mathrm{~km}$ width with thin pas abserved of about $300 \mathrm{~m}$ thickness. The flown. There, a surface-based inversion was observed of about $300 \mathrm{~m}$ thistance from the pack-ice edge. Obviously, both models were able to reproduce the boundary layer growth with a slioht underestimation of thickness and cooling at $162 \mathrm{~km}$. However, the latter could be traced back to the non-stationarity of the observed flow during the observation be traced back to the non-stationarity of the observed flow during the observation period. Neither model was able to produce the weak low-level jet observed at $300 \mathrm{~m}$ height at $51 \mathrm{~km}$. The very good agreement between the solutions of the two models with different turbulence closures (METRAS: TKE-based closure, UH: first-order mixing length scheme) is once more shown in the contour plots of potential temperature and wind in Fig. 7.6. Also, the effect of the hydrostatic approximation in the $\mathrm{UH}$ model does not generate problems in this type of flow.

Vihma et al. (2003) included a sensitivity study, in which they investigated the Vihma et al. (2003) included a sensitivity study, in which they investigated the obtained the largest effect on the boundary layer by changing the parameterization of of surface roughness. In their refernce runs, the used a paract of sea ice presface roughness by Garbrecht et al. (2002), which includes the effect of sea ice pressure ridges by splitting the entire drag into contributions of skin drag of the plane sea ice and of form drag caused by ridges. This parameterization could be used since ridge heights and their distances could be derived from the measured surface 

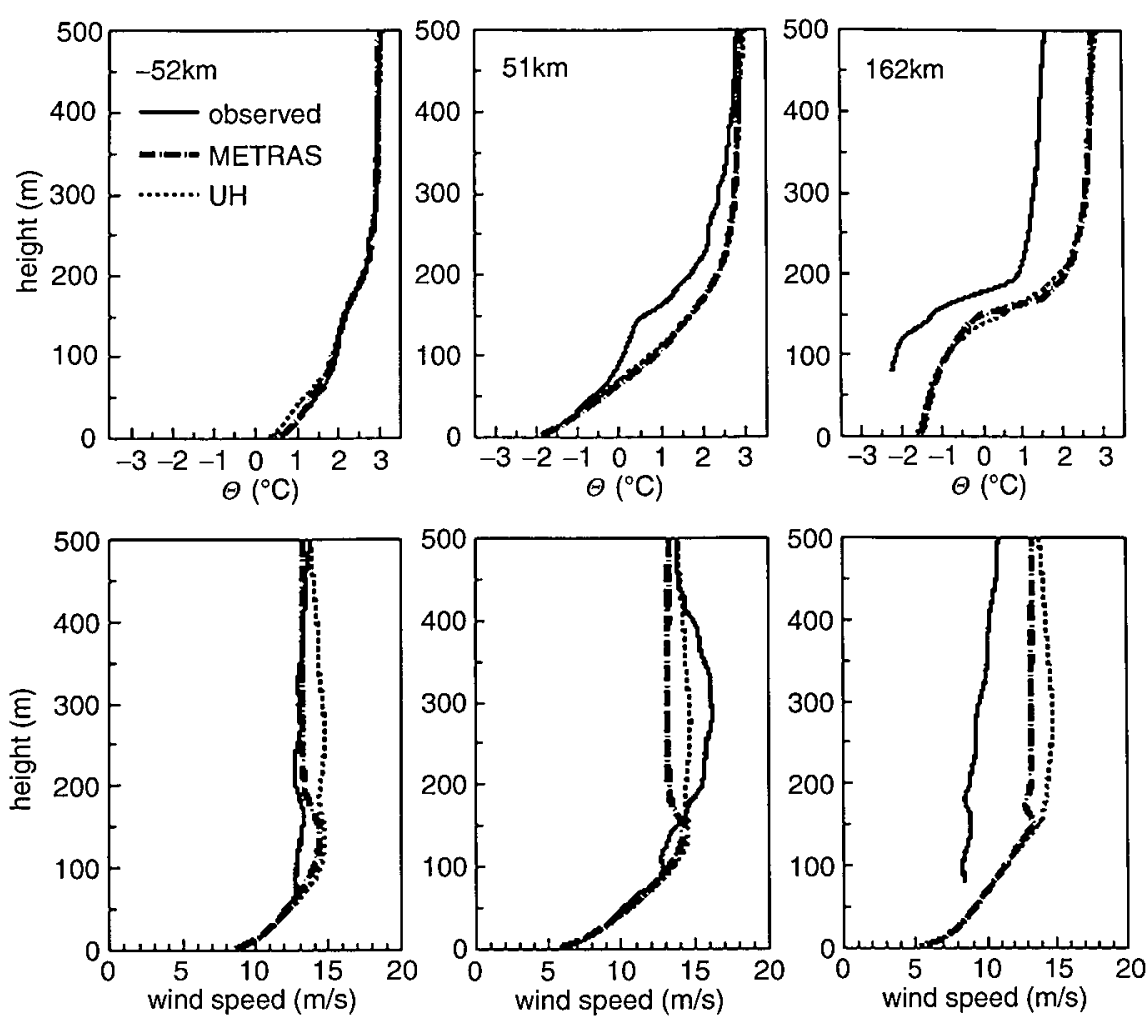

Fig. 7.5 Modelled and observed profiles of potential temperature and horizontal wind during on-ice flow over the Storfjord at different distances from the edge of the thick ice pack. The position $-52 \mathrm{~km}$ is over thin (pancake) ice, whose thickness increased towards the ice edge. Reproduced from Vihma T, Hartmann J, Lüpkes C (2003) A case study of an on-ice air flow over the Arctic marginal sea-ice zone, Boundary Layer Meteorol. 107:189-217, Figure 3, with kind permission by Springer Science+Business Media B.V.

topography. With this parameterization, a very good agreement was obtained between model results and observed near-surface fluxes (Fig. 7.7) in the region up to $100 \mathrm{~km}$ distance from the ice edge. At larger distances, the agreement was worse, which is due to the inability of the models to reproduce an observed increase of wind speed, which was probably not related to the ice surface structure.

Figure 7.7 shows that both observed and modelled momentum fluxes have a maximum at $x=0$, where $x$ is the distance from the pack-ice edge. At $x<0$, there was a region of pancake ice, and then, ice thickness and roughness increased towards $x=0$, which resulted in an increase of the drag coefficients and thus in increasing momentum fluxes. For $x>0$, two effects led to a decrease of fluxes. The first was the occurrence of smooth ice with lower observed drag coefficients, and the second one was stabilisation of the near-surface layers due to a lower surface temperature of thicker ice. As a result, in the considered case, the fluxes show an almost symmetric behaviour around $x=0$, but probably, this is not always the case over the ice edge zone.
Fig. 7.6 Potential

temperature $\left({ }^{\circ} \mathrm{C}\right)$ obtain with

two different mesoscale

models (UH and METRAS)

for on-ice flow (wind from

left to right). From Vihma T,

Hartmann J, Lüpkes C (2003)

A case study of an on-ice air

flow over the Arctic marginal

sea-ice zone, Boundary Laye

Meteorol. 107:189-217,

Figure 4, with kind

permission by Springer

Science+Business Media B.V.
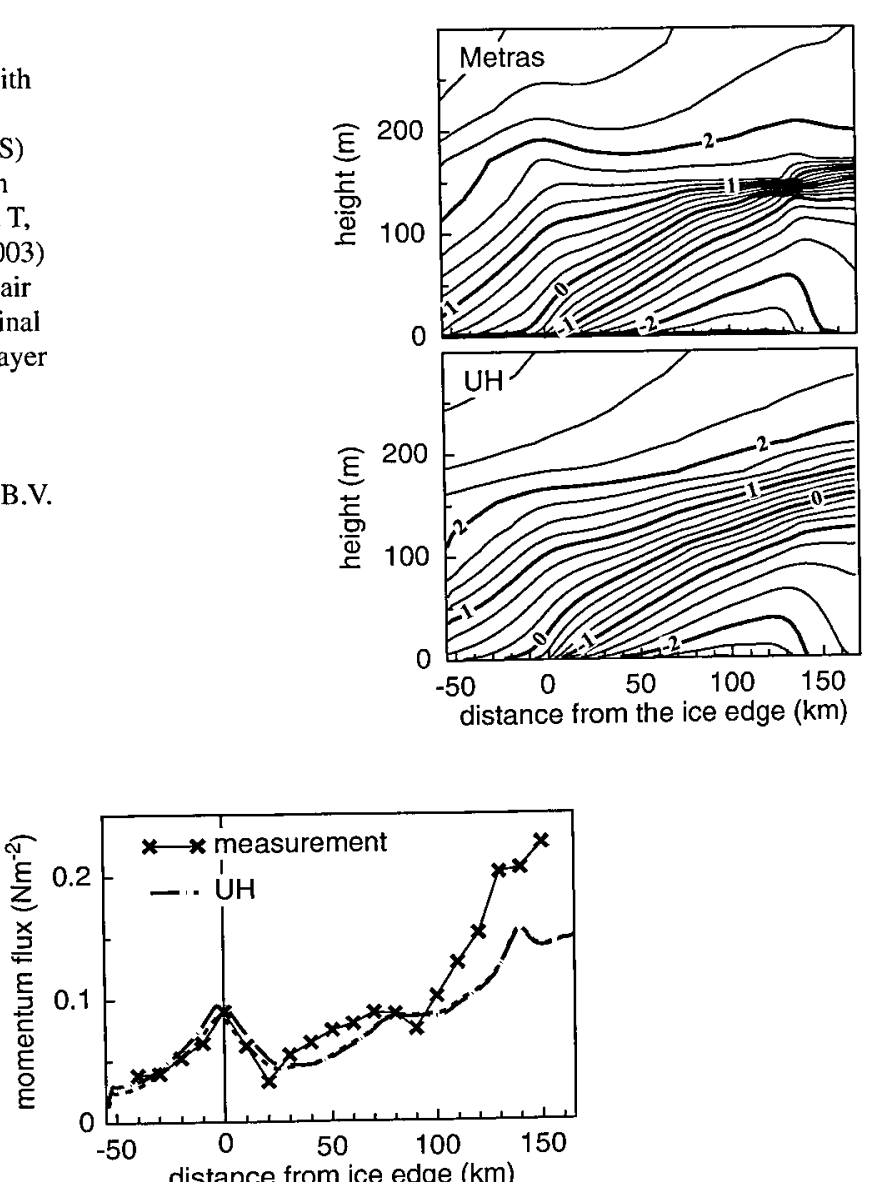
Fig. 7.7 Modelled and observed momentum flux at $30 \mathrm{~m}$ height for on-ice flow. Reproduced from Vihma T, Han sea-ice zone, Boundary Layer

Science+Business Media B.V

The effect of ridges is illustrated in Fig. 7.8 showing the difference between the METRAS model run with the form drag parameterization and with a parameterization that uses a constant roughness length for momentum $\left(z_{0}=10^{-3} \mathrm{~m}\right)$. Differences occur in the entire ABL since the modified roughness affects the ABL depth. Especially, close to its top at about $150 \mathrm{~m}$ height, the effect of a modified parameterization is large since the ABL height is influenced.

Tests with different horizontal grid sizes were also made by Vihma et al. (2003); a Tests wired for a reasonvertical resolution of more than seven layers below $500 \mathrm{~m}$ was required for a reasonable modelling of the strong inversion, and a hix regional-scale climate models, valiwas necessary. Also, experiments applying six regional-scale climate models, validated against the SHEBA data, demonstrated that the model with highest vertica resolution yielded best results for the near-surface variables (Tjernström et al. 2005). 
Fig. 7.8 Differences between two METRAS runs obtained with different surface with different surface roughness (see text). All other parameters remained unchanged. Modified from Vihma T, Hartmann J, Lüpkes C (2003) A case study of an on-ice air flow over the Arctic marginal sea-ice zone, Boundary Layer Meteorol. 107:189-217, Figure 8, with kind permission by Springer Science+Business Media B.V.

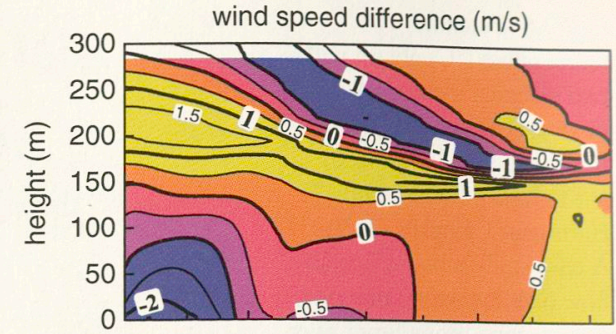

potential temperature difference $(K)$

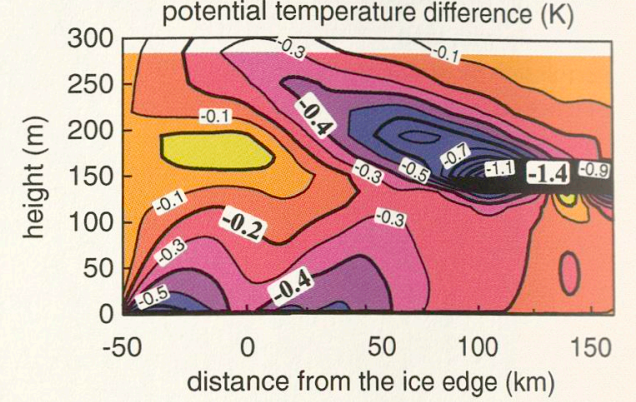

\section{Conclusions}

During ACSYS, some case studies of on-ice flow with warm-air advection have been performed with mesoscale models; the evolution of the stably stratified boundary layer over the ice has been well reproduced. Sensitivity studies under slightly stable stratification have shown that the different turbulence closure used above the surface layer have a smaller effect on the modelled boundary layer structure than the used parameterizations of surface roughness. The effect of sea ice ridges on the surface fluxes can influence wind and temperature in the entire $\mathrm{ABL}$, which is due to their impact on the $\mathrm{ABL}$ depth. Due to the shallow boundary layer and small horizontal scales of changes in roughness and boundary layer depth, the application of a higher horizontal and vertical resolution would most probably improve the performance of climate models in the Arctic even far from topography.

\subsection{Convective Processes Over Ice-Covered Oceans}

Convection in the ABL over ice-covered oceans can be generated by several factors including (1) heat fluxes from leads, polynyas and areas with thin ice; (2) strong downward longwave radiation from clouds; (3) cloud-top radiative cooling; (4) cold-air advection and (5) summertime solar radiation on an ice surface with a reduced albedo. We shall discuss the first four factors.

\subsubsection{Convection Over Leads}

The importance of leads and polynyas in generating localised convection was wel known already before the ACSYS decade. Among the first observations of the lead effect on the polar boundary layer were those carried out during AIDJEX (Paulson and Smith 1974) with measurements both in the upwind and downwind sides of leads (Andreas et al. 1979). These data clearly showed the influence of leads on the downstream profiles of wind speed and temperature. Parameterizations of the sensible heat flux were proposed as a function of bulk quantities. Further studies o leads were made by Schnell et al. (1989), who found by Lidar detection that plumes originating from leads may penetrate the Arctic inversion while transporting heat and moisture into the troposphere. According to Serreze et al. (1992a), however, such penetration is a rare event, as it requires an atypical combination of conditions (leads or polynyas at least $10 \mathrm{~km}$ wide, weak surface winds, low surface temperature and a weak temperature inversion).

During ACSYS, additional studies were carried out, resulting in more quantitative information on the fluxes over leads (Ruffieux et al. 1995; Alam and Curry 1997; Persson et al. 1997; Pinto et al. 2003). Andreas and Cash (1999) analysed hree data sets: the AIDJEX data, data from a Russian drifting station over a refrozen polynya (Makshtas 1991), and data from a polynya in the Canadian archipelago (Smith et 1983). They found that smaller leads and polynyas transport sensible (he combined effect of forced and free convection. An algorithm was proposed to calculate the turbulent heat fluxes over leads in fetch-limited convective conditions.

Attempts to model the flow over leads have been undertaken during the ACSYS Attempts to model the fow (Glendening and Burk 1992; Alam and Curry 1997; decade applying LES models (Glendening and Burk 1992; Alam and Curry 1997; Weinbrecht and Raasch 2001; Zulauf and Krueger 2003). With such models, high number of cases, which can be considered, was restricted due to the models 'high resolution and computational costs. Simpler models can, however, be used to simulate the characteristic features of the ABL above leads. Dare and Atkinson (1999, 2000) used a high-resolution mesoscale model to simulate the flow over polynyas $2-50 \mathrm{~km}$. ponent of the Coupled Ocean-Atmosphere Prediction System (COAMPS) to simulate a flow over leads in idealised summer and winter conditions. Their primary focus was on the internal gravity waves generated by leads; in summer conditions, 列 the gravity waves were related to the development of the internal boundary occurred. winter conditions, secondary circulations and intermittent wave breaking occurred.

A limitation in many studies has been that the in situ measumover sea ice only. This was circumvented by Lüpkes et al. (2004) during the campaign WARPS (Winter Arctic Polynya Study, Schauer and Kattner 2004), where turbulence measurements were obtained over leads from a mast mounted at the bow of RV Polarstern. Instruments were run, while the ship was drifting slowly across (1999) the lead with several stops, similarly as described earlier by turbence measuring system 
Helipod (Bange et al. 2002) was used for additional measurements. Over a lead, covered by nilas of $8 \mathrm{~cm}$ thickness, the sensible heat flux amounted to about $70 \mathrm{~W}$ $\mathrm{m}^{-2}$ and increased to $100 \mathrm{~W} \mathrm{~m}^{-2}$ when the nilas was destroyed by Polarstern. This demonstrates that a very accurate knowledge of the sea ice thickness is necessary for the calculation of the energy transport over a lead.

Two mesoscale modelling studies related to WARPS are discussed in the following lines: First, an application of the UH model with high resolution is explained, the model was used to simulate the convective boundary layer over leads observed during WARPS.

A $10 \mathrm{~km}$-wide region was considered with two leads occurring over the northern Fram Strait on 3 April 2003. Both leads were oriented perpendicular to the wind direction. Their widths were 1 and $2 \mathrm{~km}$ with a $4 \mathrm{~km}$-wide pack-ice patch in between. Flights with Helipod were conducted along the mean wind on eight levels below $300 \mathrm{~m}$ with the lowermost level at about $30 \mathrm{~m}$. Several vertical soundings were flown at both ends of the horizontal flight sections. A well-mixed laye over the lead was found reaching a height of $150 \mathrm{~m}$. The maximum sensible hea flux observed over the leads at the lowermost flight level was about $400 \mathrm{~W} \mathrm{~m}^{-2}$. In the UH model, a horizontal grid spacing of $250 \mathrm{~m}$ was used with 50 layers in the lowermost $3 \mathrm{~km}$. The initial $\theta(z)$ and $\mathrm{q}(z)$ for the model were set according to the upwind Helipod profile up to $400 \mathrm{~m}$ and above according to Polarstern rawinsonde sounding data. The geostrophic wind was set according to observed winds above the ABL to $10 \mathrm{~m} \mathrm{~s}^{-1}$. At the lateral boundaries, zero-gradient boundary conditions for $\theta(z), q(z)$ and $V(z)$ were used. The surface temperature was prescribed on the basis of data obtained from a radiation thermometer at the helicopter. The model was run for $2 \mathrm{~h}$.

The observed and modelled sensible and latent heat fluxes as well as potential temperatures are shown in Figs. 7.9 and 7.10. The vertical distribution of the sensible heat flux is well reproduced, but the modelled temperature increase at $30 \mathrm{~m}$ height caused by the leads is somewhat larger than observed. Further, there is a horizontal shift of $\sim 1 \mathrm{~km}$ between the observed and modelled peak values of the turbulent fluxes at the height of $30 \mathrm{~m}$.

This comparison of the hydrostatic model with the observations indicates that a non-eddy resolving model reproduces to some degree the structure of observed plumes, although the simple local turbulence closure applied was originally developed for horizontally homogeneous flow. This conclusion, however, has to be treated with some caution, since the spatial resolution of measurements was restricted, so they can give only an approximate picture of the real topology of temperature fields and fluxes over the leads.

In another modelling study (Lüpkes and Gryanik 2005; Lüpkes et al. 2008) (abbreviated by L0508) on the convection over leads, results obtained with the LES model PALM (Raasch and Schröter 2001) were compared with those of the nonhydrostatic model METRAS (Schlünzen 1990). The LES model used grid sizes of $10 \mathrm{~m}$, which was small enough to resolve lead-induced convection. METRAS, however, was run with a non-eddy resolving horizontal grid length of $200 \mathrm{~m}$. Two different turbulence closures were used in METRAS: a local mixing length closure, similar

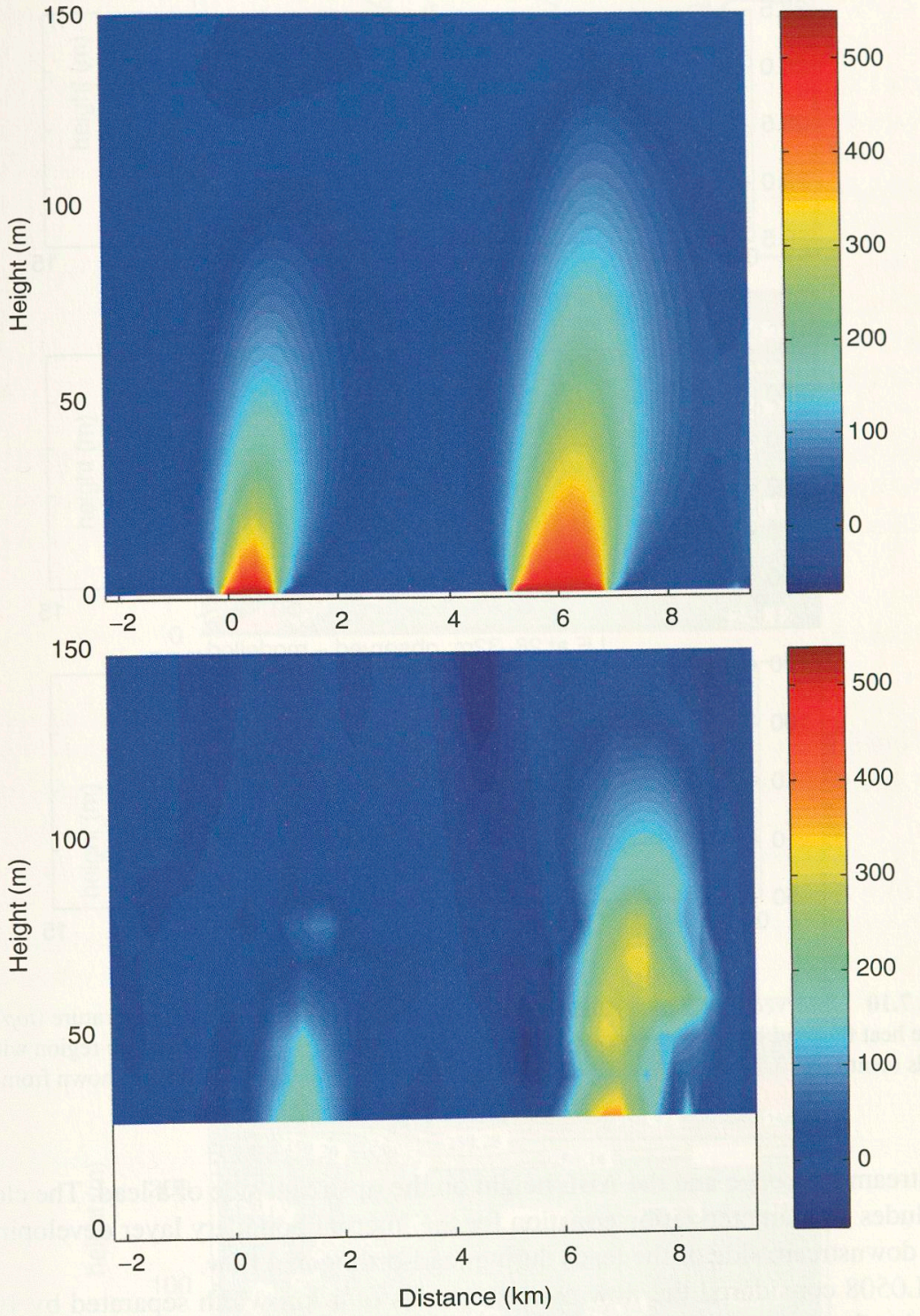

7.9 Observed (bottom) and modelled (top) sensible heat flux over two leads (at $0-1 \mathrm{~km}$ and 1 available from the layer below $30 \mathrm{~m}$ height

the one used for the result shown in Fig. 7.9, and a new nonlocal turbulence closure, which accounts for the inhomogeneous nature of the flow over leads and clom allows gradient and countergradien flux over the lead surface, the wind speed the 

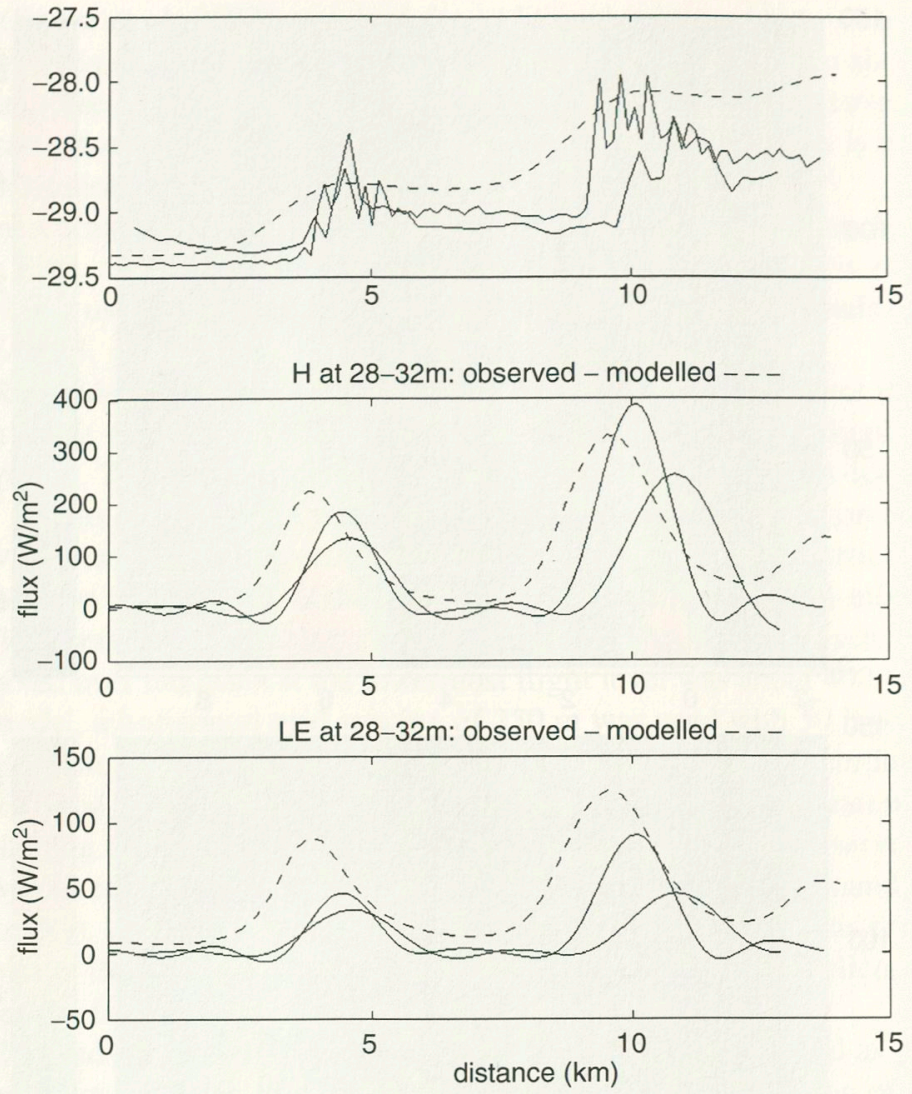

Fig. 7.10 Observed (solid lines) and modelled (dashed line) air potential temperature (top), sensible heat flux and latent heat flux at the height of $30 \mathrm{~m}$ over a $12 \mathrm{~km}$-wide sea ice region with two leads (centred at 3.5 and $9.5 \mathrm{~km}$ ). Two low-level flights were made, and data are shown from both

upstream lead edge and the ABL height on the upstream side of a lead. The closure includes a parameterization equation for the internal boundary layer developing on the downstream side of the leads during lead-orthogonal flow.

L0508 considered the flow over two leads of $1 \mathrm{~km}$ width separated by $10 \mathrm{~km}$ sea ice from each other. A neutral boundary layer was prescribed initially at the inflow boundary of the first lead with a strong capping inversion at $300 \mathrm{~m}$ height. In Fig. 7.11, results of both models are shown. Only by application of the nonlocal closure to METRAS, it became possible to reproduce the distribution of potential temperature as obtained from the LES model. Obviously, in both model results, the potential temperature decreases with height only in a small region over the lead. However, in a much larger region downstream of the lead, it increases slightly with height. Also, the simulated plume inclinations agree well in both model results.
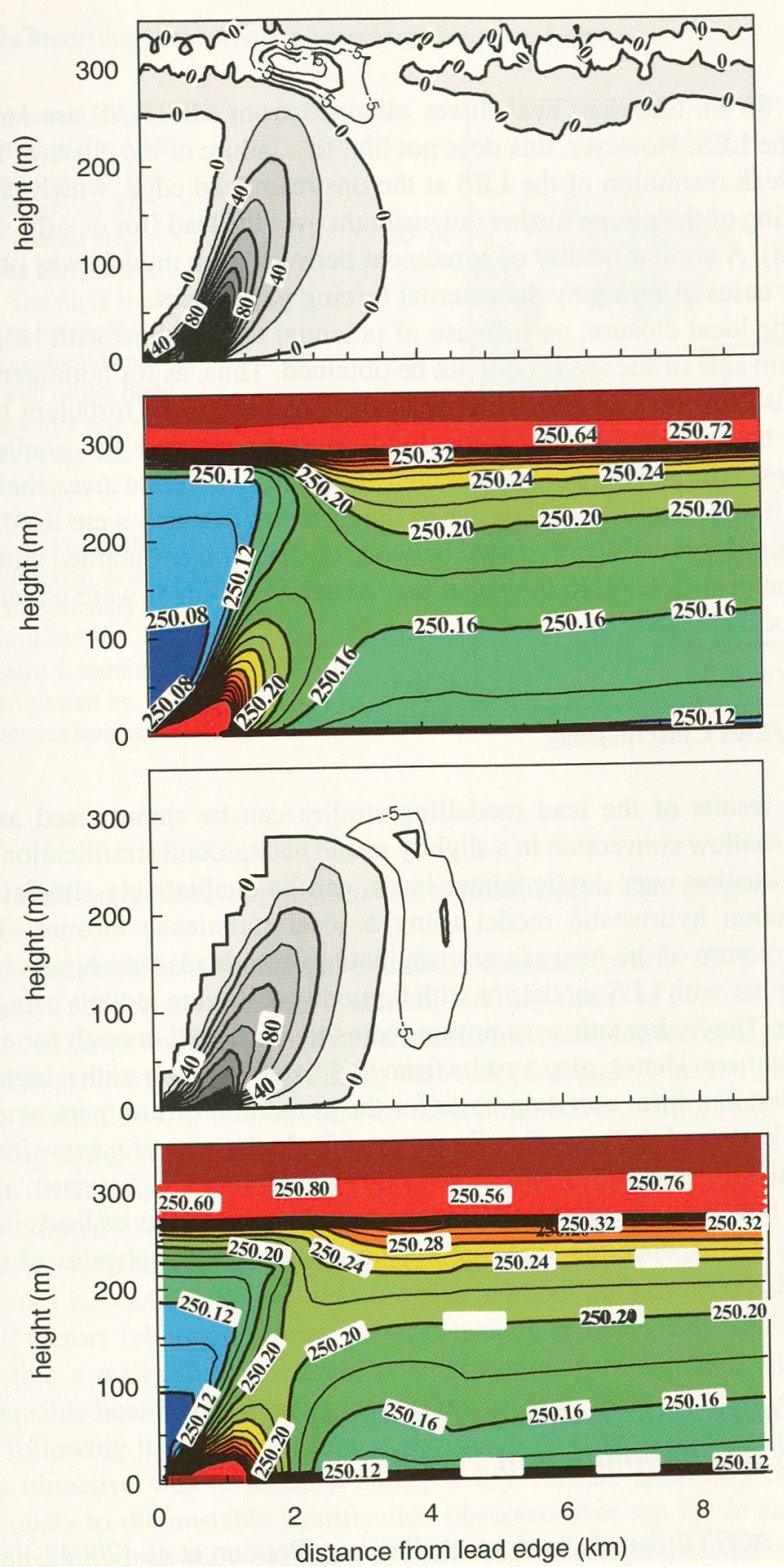

Fig. 7.11 Potential temperature $(\mathrm{K})$ and sensible heat flux $\left(\mathrm{W} \mathrm{m}^{-2}\right)$ obtained from the LES model (two top figures) and from METRAS (two bottom figures). The lead position is between distance $=0$ and distance $=1 \mathrm{~km}$; surface wind of about $5 \mathrm{~m} \mathrm{~s}^{-1}$ is directed in this case from left to right. Similar model results are described in From Lüpkes C, Gryanik VM, Witha B, Gryschka M, Raasch S, Gollnik T (2008) Modelling convection over leads with LES and a non-eddy-resolving microscale model. J Geophys Res C09028, Figures 3 and 6, Copyright American Geophysical Union (2008), modified by permission of American Geophysical Union 
Below $80 \mathrm{~m}$, turbulent heat fluxes obtained from METRAS are smaller than those of the LES. However, this does not hint to a failure of the closure. The reason is a too weak resolution of the LES at the upstream lead edge, which produces an overshooting of the plume further downstream over the lead (for details, see Lüpkes et al. 2008). A similar quality of agreement between both models was obtained for nine other cases differing by the external forcing parameters.

With the local closure, an increase of potential temperature with height on the downstream side of the lead could not be obtained. Thus, as for homogeneous convection, also for the lead situation, the physical nature of the turbulent heat fluxes could not be reproduced since a local closure accounts only for gradient fluxes Nevertheless, the temperatures, averaged in vertical direction over the boundary layer depth, differed only slightly when the different closures were used. A difference in the order of $10 \mathrm{~W} \mathrm{~m}^{-2}$ existed between the heat fluxes obtained with the loca and the nonlocal closure. In the upper part of the ABL, fluxes were underestimated with the local closure.

\section{Summary and Conclusions}

The main results of the lead modelling studies can be summarised as follows: Localised shallow convection in a slightly stable background stratification, which is a typical situation over Arctic winter leads, can be qualitatively simulated with a high-resolution hydrostatic model using a local turbulence closure. The more detailed structure of the heat plumes originating from leads can, however, only be resolved either with LES models or with non-eddy-resolving models using a nonlocal closure. The hydrostatic assumption seems to work well enough for conditions as presented here. Hence, also, results from hydrostatic models with a high horizontal resolution can form a certain basis for the derivation of flux parameterizations over large leads and polynyas for climate models. In the case of narrow leads, additional detailed observations and large eddy simulations are, however, needed to clarify the flow regimes. More studies are needed on the effects of leads in generating gravity waves since the latter are very important for the physics of the stable Arctic ABL.

\subsubsection{Convection Over Sea Ice Caused by a Combination of Factors}

During the ACSYS decade, various studies, e.g. Persson et al. (2002), have documented that the ABL stratification over Arctic sea ice can be slightly unstable even in winter, and the effects of various individual factors in generating the unstable stratification have been addressed. The heat budget of the ABL over sea ice is affected by turbulent, radiative and advective processes. During warm-air advection from the open ocean to sea ice, the stratification is typically stable (Sect. 7.3), but
Fig. 7.12 Horizontal flight legs (solid lines) of the AWI Polar 2 aircraft over sea ice Polar 2 aircraft over sea iz east of Spitsbergen on 27 March 198. Islands are marked in grey and the sea ice in white. The flight track was completed by profile fights at the upstream and downstream end of the fligh legs and by another one at about $24.5^{\circ} \mathrm{E}$. From Vihma T, Lüpkes C, Hartmann J, Savijärvi H (2005)

Observations and modelling of cold-air advection over Arctic sea ice. Boundary Artic sea ice. Boundary 275-300, Figure 1, modified with kind permission by with kinger Science+Business Springer Scienc.
Media B.V.

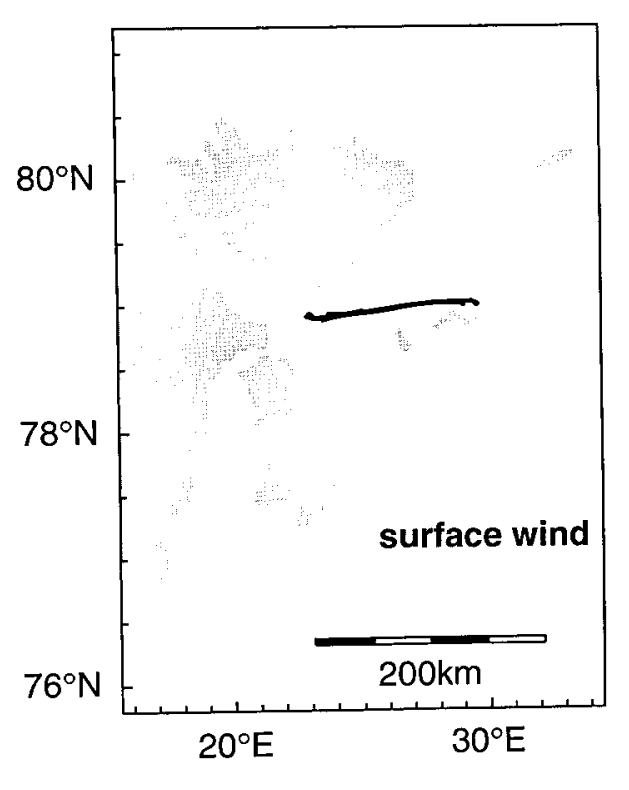

during cold-air advection, slightly unstable stratification can be generated also over sea ice.

In winter, unstable stratification over a thick, compact (nearly $100 \%$ ice concentration) Arctic sea ice cover is less common, but may occur in overcast conditions with enhanced downward longwave radiation from clouds (Intrieri et al. 2002). This was one of the important findings during the ACSYS decade. Further, Pinto (1998) and Wang et al. (2001) found out that cloud-top radiative cooling may cause topdown mixing and generate a convective $\mathrm{ABL}$ even without any major heating from the surface. In the study of Vihma and Brümmer (2002), a slightly convective ABL the surface. In the study of

In summer, with a larger incoming solar radiation and a lower surface albedo, the $A B L$ over sea ice can be slightly unstable even without the presence of the abovementioned factors (although a cloud cover is usually present). The SHEBA results mentioned factors (although a cloud cover is usually present). The SHEBA results indicated that a well-mixed boundary layer is common in summ

In the following lines, a modelling study of Vihma et al. (2005) is described in In the following lines, a modelling study of simultaneously to the unstable stratification observed over sea ice in early spring. The me ABL over Arctic sea ice east of Spitsbergen (Fig. 7.12). Non-stationary conditions of cold-air advection prevailed with a cloud-covered area, whose edge was retreating through the study region. Four horizontal legs of $100 \mathrm{~km}$ length were flown back and forth in study region. Four har al a vertical profiles were measured. In the following figures (Figs. 7.13 and 7.14), the 

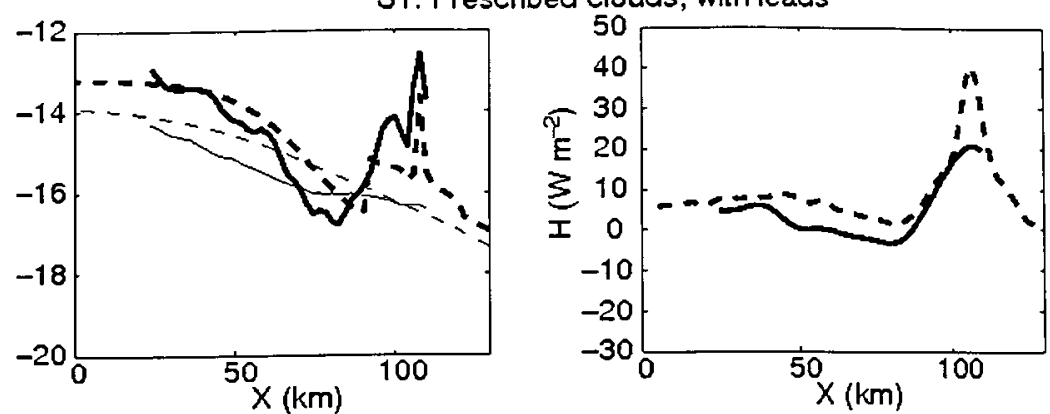

S2: Prescribed clouds, no leads
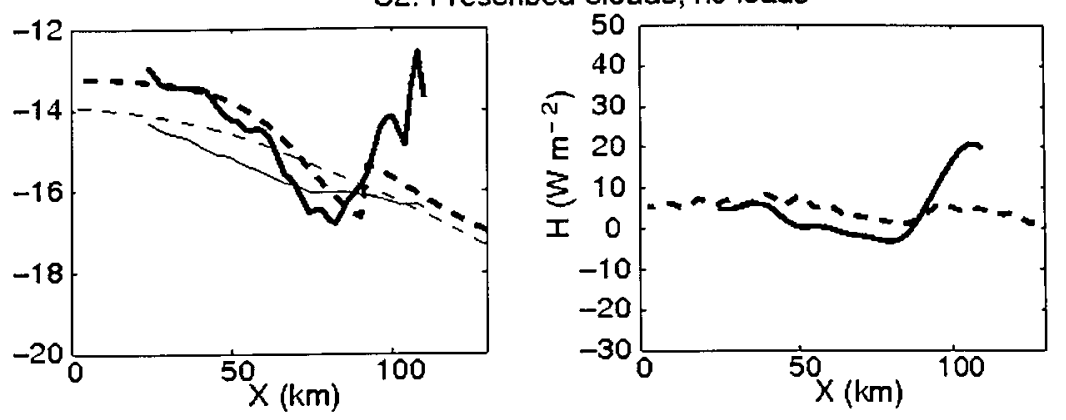

S3: No clouds, with leads
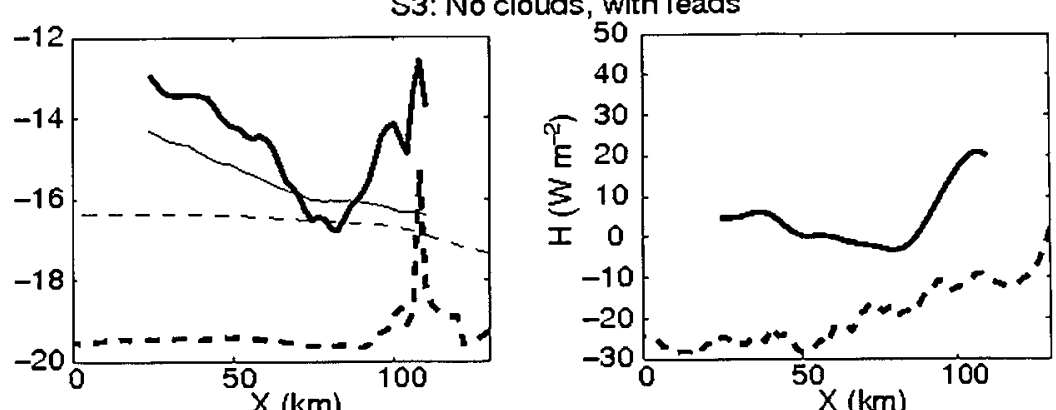

S4: No clouds, no leads
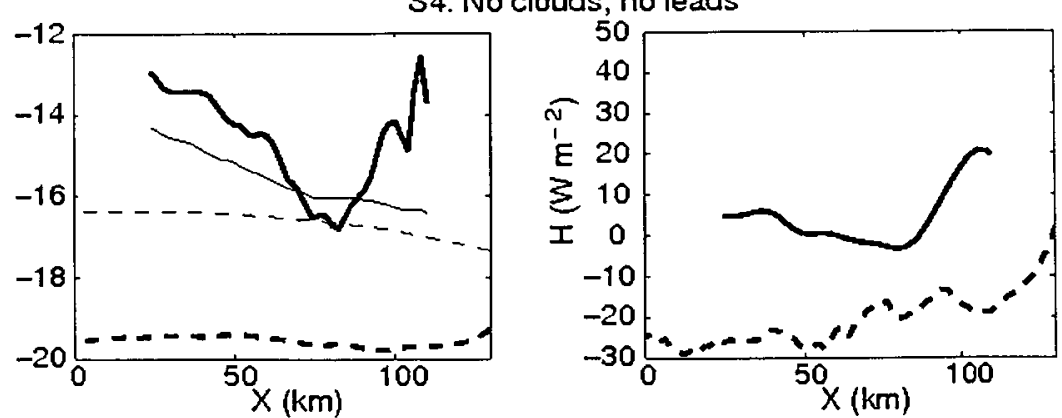

Fig. 7.13 Observed (continuous lines) and modelled (dashed lines) horizontal distributions from east (left) to west (right) of the potential temperature in ${ }^{\circ} \mathrm{C}$ (left column) of the surface (thick lines) and air (thin lines) and the sensible heat flux averaged over the four low-level flight legs for the sensitivity tests S1-S4. From Vihma T, Lüpkes C, Hartmann J, Savijärvi H (2005) Observations and modelling of cold-air advection over Arctic sea ice. Boundary Layer Meteorol 117(2):275-300, Figure 10, with kind permission by Springer Science+Business Media B.V.
7 Mesoscale Modelling of the Arctic Atmospheric Boundary Layer...
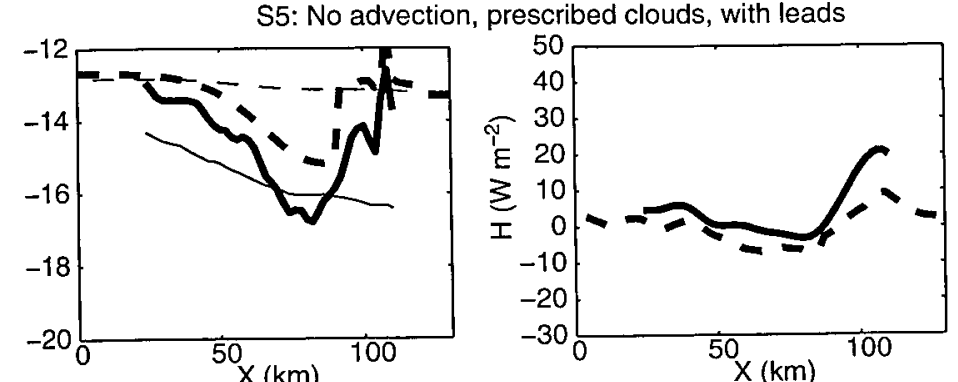

Fig. 7.14 As Fig. 7.13, but for sensitivity test, S5 without the effect of cold-air advection. From Fig. 7.14 As Fig. 7.13, but for se Vhm T, Litkes C. Hict tion over Arctic sea ice. Boundary Layer Meteo
sion by Springer Science+Business Media B.V.

$x$-coordinate is defined, increasing eastwards with $x=0$ at $23^{\circ} \mathrm{E}$, where the westernmost vertical profile was flown (Fig. 7.12). The turbulent fluxes of momentum, sensible heat and latent heat were calculated from the instantaneous observations. The sea ice concentration, roughness and ABL stratification varied along the fligh The se in the west was compact, but in the east 1most $30 \mathrm{~km}$ wide with small leads covering $5 \%$ of the surface area.

The observed case was modelled, applying the UH 2D hydrostatic boundary yer model equipped with a good-quality (modified ECMWF) radiation scheme ee also Sects. 7.3 and 7.4.1). To better understand the reasons for the spatial variaons and for the existence of a well-mixed boundary layer with unstable stratificaabove the surface, different model runs were carried out. Five of these runs are scribed as follows:

S1: The surface temperature was modelled with an eight-layer scheme for the heat conduction in the snow and ice. The surface of each grid interval was divided into subsections of snow-covered ice and leads on the basis of the observations. The grid-averaged surface fluxes of heat and moisture were then calculated as area averages of the local fluxes, applying the mosaic method (Vihma 1995). Time-dependent vertical profiles of potential temperature and specific humidity at the inflow boundary, the cloud cover and the surface roughness were prescribed according to the observations. The flow was forced by the geostrophic wind speed based on the observations.

2: As S1, but no leads were included.

3. As $S 1$, but no clouds were included.

S4: As S1, but no clouds and no leads were included.

55. As $S 1$, but instead of the prescribed $\partial \theta(\mathrm{z}), \mathrm{t}$ at the inflow boundary, zerogradient boundary conditions were applied. Accordingly, in S5, there was no large-scale cold-air advection into the model domain.

In S1, the results (Fig. 7.13) are close to the observations, although the sensible he flux is overestimated in the lead region, as is also the air temperature in the middle of the study region. The success of S1 was naturally mostly based on the 
prescribed clouds. However, the same cloud condensate contents and cloud fractions based on observations were used in all other model runs with clouds included (S2 and S5). This approach is supposed to yield reliable results on the relative importance of clouds, leads and advection.

In S2, with prescribed clouds, but without leads, the surface temperatures are too cold in the lead region at the western part of the domain, and the sensible heat flux does not show any peak there. In S3, with leads but without clouds, $\theta_{\mathrm{s}}$ is far too low, resulting in a downward sensible heat flux. In S4, with no clouds and no leads, the situation is almost the same as in $\$ 3$, except for the surface temperature peak.

On the basis of the results of $\mathrm{S} 1-\mathrm{S} 4$, it appeared that, under cold-air advection conditions, the thick clouds were responsible for the upward sensible heat flux in the downwind region, while leads together with thin clouds caused the upward flux in the upwind region. The effects of leads and clouds interacted non-linearly with the ABL turbulence and advection: in the presence of clouds, the lead effect on the $\mathrm{ABL}$ appeared stronger than in the absence of clouds (Fig. 7.13).

To understand the importance of the imposed cold-air advection, we look at the model results without it (S5, Fig. 7.14). $\theta_{s}(x)$ is warmer than in $S 1 ; \theta_{40 m}(x)$ is much warmer, and it is constant downstream. The sensible heat flux displays only a weak positive peak in the upwind region. The results accordingly suggest that the observed upward sensible heat flux was a combined effect of clouds, leads and cold-air advection.

Vihma et al. (2005) also made 5-day simulations to study the quasi-steady-state structure of the cloudy ABL over the Arctic sea ice. The simulations demonstrated that the evolution towards a deep, well-mixed ABL may take place via a formation of two mixed layers: one related to mostly shear-driven surface mixing and the other to buoyancy-driven top-down mixing due to the cloud-top radiative cooling. These mixed layers may gradually merge. The results were comparable to those of Wang et al. (2001) The combined effects of shear-driven turbulence and cloud-top radiative cooling over Arctic sea ice were addressed also in the LES modelling study by Inoue et al. (2005).

\section{Summary and Conclusions}

The effects of several factors acting simultaneously on the ABL development have received little attention in earlier studies. Studies during the ACSYS decade demonstrated that the important factors influencing the surface layer stratification are downward longwave radiation from clouds, upward heat fluxes from leads and cold-air advection. Qualitatively similar results have been derived from analyses of the Russian ice station data (Vihma and Pirazzini 2005). From the point of view of the ABL temperatures and stratification, clouds are usually more important than leads since they can strongly shape the temperature profile via both cloud-top radiative cooling (generating top-down mixing) and radiative heating of the snow surface (generating turbulent surface flux and bottom-up mixing).

\subsection{Mesoscale Studies with Coupled Atmosphere-Sea Ice Models}

A detailed understanding of the atmosphere-sea ice interaction requires the application of models on different scales including the mesoscale. Before the ACSYS decade, studies with coupled models were mainly restricted to large-scale models or to 1D models, and only very few investigations were made with multidimensional mesoscale models. One of the first studies was carried out by Wefelmeier (1992) (see also Wefelmeier and Etling 1991), who considered ice drift in the Fram Strait and its interaction with the ABL. The ice model did not include thermodynamic processes. During ACSYS, more complex coupled mesoscale atmosphere-sea ice models have been developed. A two-class dynamic-thermodynamic coupled atmosphere-sea ice model has been applied for studies of coastal polynyas (see Sect. 7.6). The results of the present section are based on the METRAS/MESIM model, which has been developed at the University of Hamburg in cooperation with the Alfred Wegener Institute, Bremerhaven. It consists of the atmospheric mesoscale model METRAS (see the previous subsections of Chap. 7) and the mesoscale sea ice model MESIM (Birnbaum 1998; Dierer et al. 2005). MESIM simulates the drift as well as freezing and melting of sea ice for several ice categories.

During the ACSYS decade, the model has been applied by Birnbaum (1998), by Dierer et al. (2005) and by Dierer and Schlünzen (2005). In the latter two articles, the impact of a cyclone passage on sea ice is studied. A similar case is considered in the following Sect. 7.5.1, and another application of the model system, based on Birnbaum (1998), is described in Sect. 7.5.2. In these studies, the thermodynamic effects are neglected in respect of the short time scales considered. The ice model is directly coupled to METRAS by using a flux aggregation scheme according to von Salzen et al. (1996). It includes the form drag effect of floe edges as in Birnbaum and Lüpkes (2002) (see also Sect. 7.5.2). A partial sea ice cover is allowed in each model grid cell. In each time step, the atmospheric forcing is used to calculate the ice drift and in return, the new ice distribution influences the atmosphere by changing for example, roughness length and heat flux. The influence of the ocean current is considered for the ice drift as well, but the changes in ocean currents by atmospheric forcing are not considered.

\subsubsection{Influence of Polar Mesoscale Cyclones on Fram Strait Sea Ice Export - Case Studies with the Mesoscale Model System METRAS/MESIM}

Every 5-6 days, a low-pressure system is passing the Fram Strait region (Affeld 2003). Based on ECMWF reanalysis data, Affeld (2003) additionally shows that $13 \%$ of the 1,374 lows that occurred between 1979 and 2000 in the Fram Strait were moving in northerly direction and thus passing the marginal sea ice zone, where 


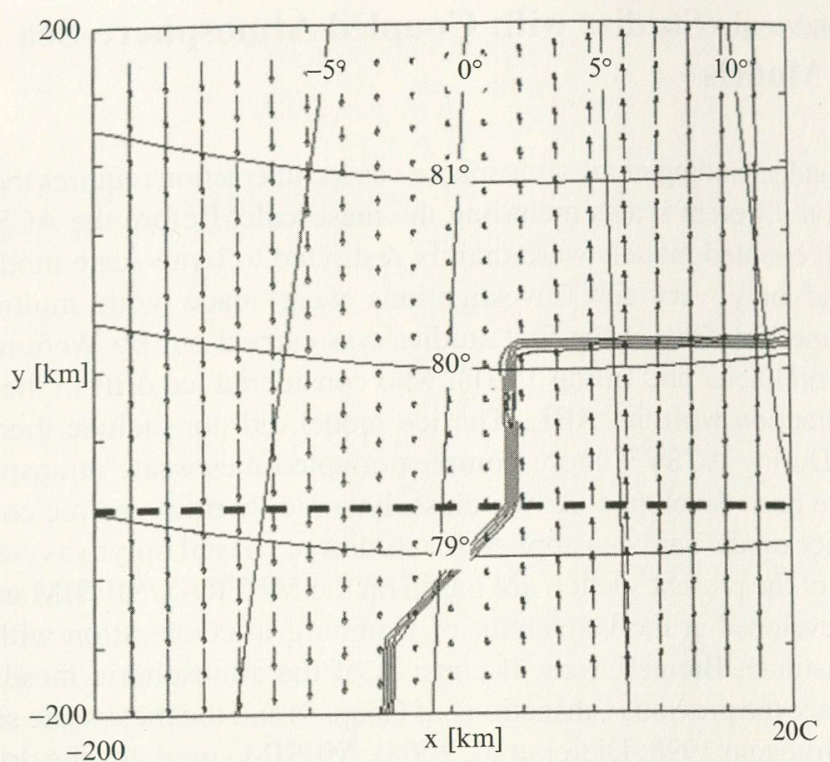

Fig 7.15 Ocean current (vectors) and ice edge ( grey line) in the Fram Strait. The region south and east from the ice edge is ice free in cases A and B. The dashed line denotes the budgeting line for east from the ice edge is ice free in case
calculating ice export and average wind

they strongly influence the energy exchange between ocean and atmosphere as wel as the drift of sea ice. A study with METRAS/MESIM has been carried out to gain a better understanding of the atmosphere-sea ice interaction in such conditions and to quantify the modification of the ice export induced by a mesoscale low.

METRAS/MESIM was set up for the Fram Strait with the model domain completely over water and ice without any land surfaces included (Fig. 7.15). The passage of a mesocyclone was simulated for springtime meteorological conditions with ABL temperatures between $-10^{\circ} \mathrm{C}$ and $-30^{\circ} \mathrm{C}$ depending on the underlying surface type. The prescribed large-scale pressure gradient forced a cyclone track from south to north. The centre of the cyclone passed the model domain across its centre. This means that the atmospheric flow was from south to north in the eastern part of the domain and in the western part vice versa, when the cyclone centre was above the domain centre. Different scenarios were considered. The characteristics of the basic case A can be summarised as follows: ocean flow and ice coverage were used as shown in Fig. 7.15. A southward ocean current was prescribed in the western and northward current in the eastern part of the model domain. This type of ocean current is typically found in the Fram Strait. The ice coverage amounted to $97 \%$ in the ice-covered sector of the domain and to $75.7 \%$ on average in the entire domain Case A corresponds to a situation that was observed during the campaign ARKTIS' 93 (Brümmer and Höber 1999). The sea ice distribution is characteristic for the northern Fram Strait region and is found in the climatological average.
Table 7.1 Parameters for run A and parameters used in the sensitivity studies B and C

\begin{tabular}{ll}
\hline Case & Changed parameter \\
\hline $\mathrm{A}$ & Ice coverage in the ice-covered region $97 \%$, total ice coverage $75.7 \%$ \\
$\mathrm{~B}$ & No ocean flow, ice field as in A
\end{tabular}

No ocean flow, ice field as in $\mathrm{A}$

Homogenous ice coverage of $75 \%$ in the entire domain

Fig. 7.16 West-east average modelled wind speed $f f$ and direction $d d$ at the budgeting line for cases A-E

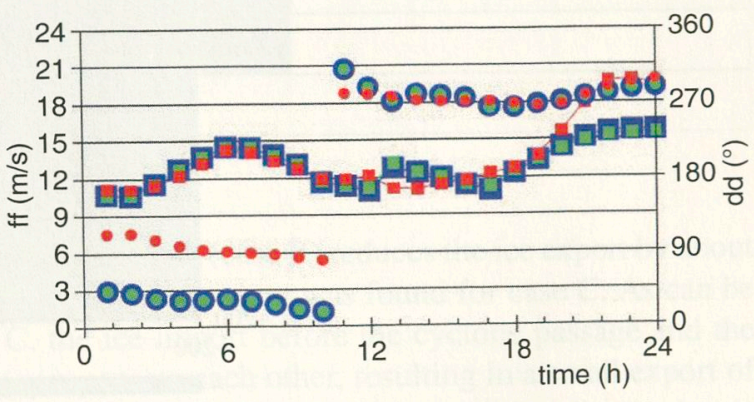

$=f f A-f f b-f f c \bullet d d A \cdot d d B \cdot d d C$

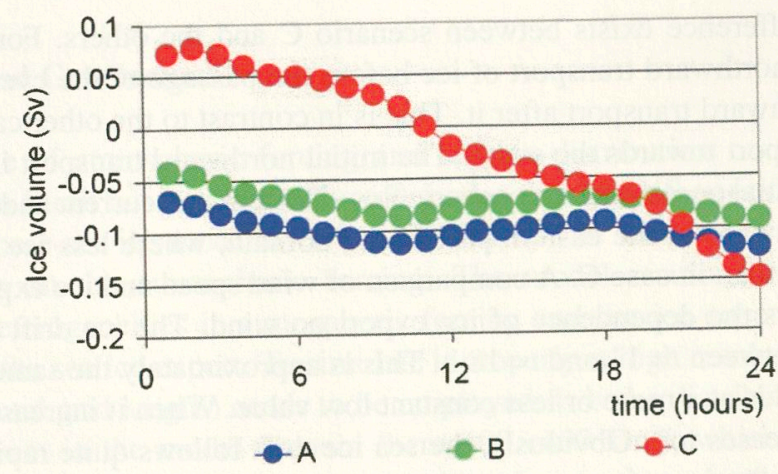

Fig-7.17 West-east averaged ice volume transport at the budgeting line. Positive values denote ice transport to the north (import to the Arctic); negative values indicate ice transport to the south (export from the Arctic)

Two further model runs were carried out. In case B, the ocean flow was assumed as the sea ice remained unchanged. In case C, a homogenous sea ice cover of $75 \%$ was prescribed in the entire domain (Table 7.1); the ocean flow was as in case A.

The modelled wind speed as well as the wind direction at the budgeting line Fig 7.15) varies speed (Fig. 7.15) varies considerably during the simulation (Fig. 7.16). The wind speed maximum amounts to $16 \mathrm{~m} / \mathrm{s}$ at the end of the runse passes the budge line $10 \mathrm{~m} / \mathrm{s}$ at the beginning. The centre of the cyclone passes the budgeting line turns by about $40^{\circ}$ to $t=10 \mathrm{~h}$. At that time, the average from a previous maximum value of $15 \mathrm{~m} / \mathrm{s}$ to the east, and the wind speed drops from a previous maximum value of 15 mown in Fig. 7.17. 
Fig. 7.18 Ice coverage at $t=24 \mathrm{~h}$ for case A

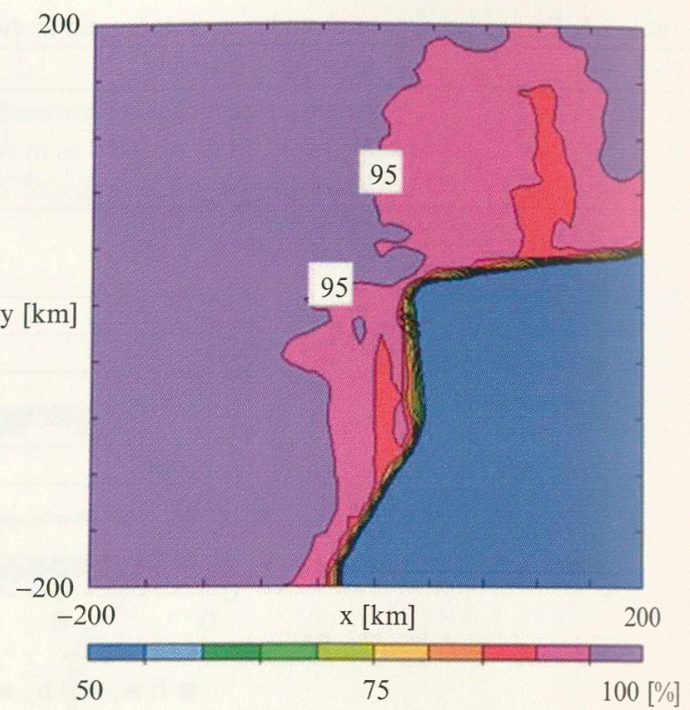

The largest difference exists between scenario $\mathrm{C}$ and the others. For scenario C, there is a net northward transport of ice before the passage of the cyclone's centre and a net southward transport after it. This is in contrast to the other cases showing always a transport towards the south. The initial northward transport in case $\mathrm{C}$ is a result of the initial ocean and atmospheric flow. Both, ocean current and atmospheric flow, are northward in the eastern part of the domain, where less ice exists in the cases A and B than in case C. A comparison of wind speed and ice export for cases $\mathrm{A}$ and $\mathrm{B}$ shows the dependence of ice export on wind. The ice drift export has a saddle point between $t=11$ and $t=18 \mathrm{~h}$. This is approximately the same time, when the wind speed is at a more or less constant low value. When it increases again, the ice export increases too. Obviously, the sea ice drift follows quite rapidly changes in atmospheric forcing.

The wind direction is the other important impact factor: south-easterly winds before the cyclone passage advect ice towards the ice-covered west. This ice is loosened after the cyclone passage by the north-westerly winds, which advect ice to the open water in the south-east. The ice distribution after the cyclone passage (Fig. 7.18) reflects the large impact of the cyclone. Close to the ice edge, the ice coverage is reduced by up to $10 \%$ (case A) and by about the same amount in the centre of the formerly homogeneous ice cover in case C. During the cyclone passage, the modelled ratio ice drift/wind speed increases, which is confirmed by observations of Brümmer and Hoeber (1999). This is most probably caused by the loosening of the ice. Hence, the increase in ice export in all cases is a combined effect of the increase of the ice drift/wind speed ratio, the changed wind direction and the larger wind speeds after the cyclone passage.

The total effect of the different scenarios for the initial ice distribution and ocean flow can be derived from the ice export across the budgeting line averaged over $24 \mathrm{~h}$
Fig. 7.19 Mean ice export (Sv) at the budgeting line $\left(795^{\circ} \mathrm{N}\right)$ for scenarios $A, B$ and $C$

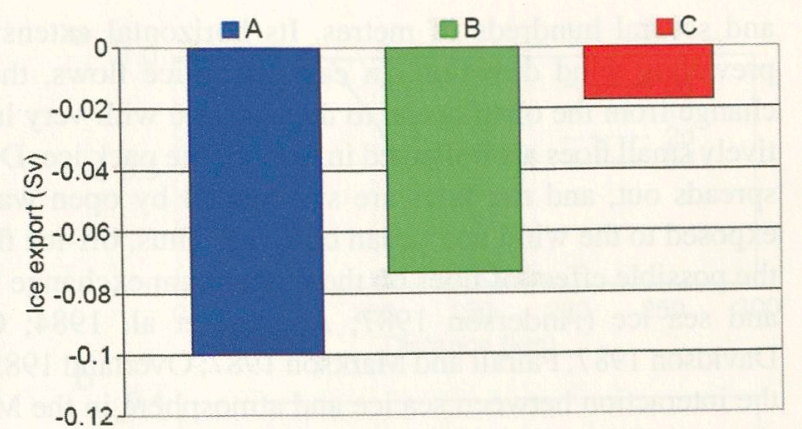

(Fig. 7.19). The neglect of the ocean current (case B) reduces the ice export by about $27 \%$ compared to case A. The smallest ice export was found for case C. As can be seen from Fig. 7.17, in case C, the ice import before the cyclone passage and the export thereafter more or less compensate each other, resulting in a small export of only $0.017 \mathrm{~Sv}$ for the $24 \mathrm{~h}$ integral. Obviously, the small-scale ice distribution is crucial to properly simulate ice export.

\section{Summary and Conclusions}

The influence of atmospheric forcing and sea ice distribution on sea ice export through Fram Strait has been investigated during the ACSYS period with the coupled atmosphere-sea ice model METRAS/MESIM. The sea ice was found to react within hours on the atmospheric forcing. The model results have shown that mesoscale heterogeneities in atmospheric forcing and sea ice cover can considerably change the sea ice export. To simulate it properly, a high resolution (here with $7 \mathrm{~km}$ horizontal grid length) needs to be employed. It is the distribution of ice, not $7 \mathrm{~km}$ horizontal grid length) needs to be employed. It is the der mines differences in ice export. In the considered case, the export is considerably lower for a homogeneous ice distribution within the model domain without any clear ice edge. This is due to compensating effects of ice import and export in the homogeneous case. The latter result is especially important for climate modelling since it shows that models with large grid sizes in the order of $100 \mathrm{~km}$ can produce serious errors in modelling the ice export.

\subsubsection{Modelling of Sea Ice Drift in the Marginal Sea Ice Zone}

The interaction of atmosphere, ocean and sea ice is particularly strong in areas with heavily ridged ice or with a broken ice cover. Such conditions are typical for the marginal sea ice zone (MIZ), which is the transition zone between the pack ice and marginal sea ice zone (Mith 
and several hundreds of metres. Its horizontal extension mostly depends on the prevailing wind direction. In case of on-ice flows, there is sometimes a sudden change from the open ocean to the pack ice with very large floes. Sometimes, relatively small floes are collected in front of the pack ice. During off-ice flows, the MIZ spreads out, and the floes are surrounded by open water. Hence, their edges are exposed to the wind and ocean currents. Thus, off-ice flows are ideal to investigate the possible effect of floes on the momentum exchange between atmosphere, ocean and sea ice (Anderson 1987; Andreas et al. 1984; Claussen 1991; Guest and Davidson 1987; Fairall and Markson 1987; Overland 1985). Birnbaum (1998) studied the interaction between sea ice and atmosphere in the MIZ with the coupled model system METRAS/MESIM (see Sect. 7.5.1). The goal was to investigate the role of the different stress terms in the momentum balance equation for sea ice on the sea ice drift. In the following lines, this study is summarised including some additional figures not shown in the original work:

The atmospheric drag in the MIZ is calculated in METRAS as the sum of skin drag and form drag caused by floe edges and ridges at the edges of floes. This parameterization was developed during the ACSYS decade by Birnbaum and Lüpkes (2002) as well as Lüpkes and Birnbaum (2005). It is based on aircraft observations of turbulent fluxes above the MIZ during the campaign REFLEX (Kottmeier et al. 1994; Mai et al. 1996). The total drag on sea ice is parameterized in the model as the sum of the atmospheric skin drag and form drag, the oceanic skin drag and form drag, and the wave radiation stress. A similar concept as for the parameterization of atmospheric drag is used in MESIM for the calculation of oceanic stress. It is based on Steele et al. (1989), Perrie and $\mathrm{Hu}$ (1997) and Hehl (1997). The oceanic skin drag at the bottom of the ice is calculated similarly to McPhee (1979), whose approach is widely used in ice modelling (Lemke et al. 1990; Kreyscher et al. 2000). In the studies presented, the geostrophic ocean current is set to zero. As argued by Gallee (1997) and used in other coupled models (Lynch et al. 1995), this assumption is acceptable for short-time simulations.

Following Steele et al. (1989), the wave radiation stress is parameterized as a function of the surface wind stress over open water. It is assumed to point into the same direction as the near-surface wind. Internal ice forces are calculated with the most widely used viscous-plastic rheology (Hibler 1979; Lemke et al. 1990).

An off-ice flow across the Fram Strait MIZ close to Svalbard is investigated, which was also considered by Birnbaum and Lüpkes (2002) using METRAS without the sea ice model. The meteorological conditions are similar to cases typically observed during the campaign REFLEX.

The 2D model domain of $300 \mathrm{~km}$ extension is oriented in north-south direction from the pack-ice region across a large MIZ of $76 \mathrm{~km}$ length to the ice-free ocean. In the MIZ, initially, the ice concentration decreases linearly towards the open ocean (Figure 7.20a). Ice thickness and floe length are prescribed initially as a function of the sea ice concentration as proposed by Mai (1995) (see also Lüpkes and Birnbaum 2005).

In the model simulations, the geostrophic wind is set to $10 \mathrm{~m} \mathrm{~s}^{-1}$ from north. This direction is perpendicular to the model's east-west oriented ice edge. Sea water is concentration $\mathrm{A}$ in the initial state and after 1,2 and 3 days (b) Absolute value of ice drift (b) Absolute vacio velocity $v_{i}$ in the initial state and after 3 days as a function of distance from the northern (inflow) boundary. The results refer to case 1

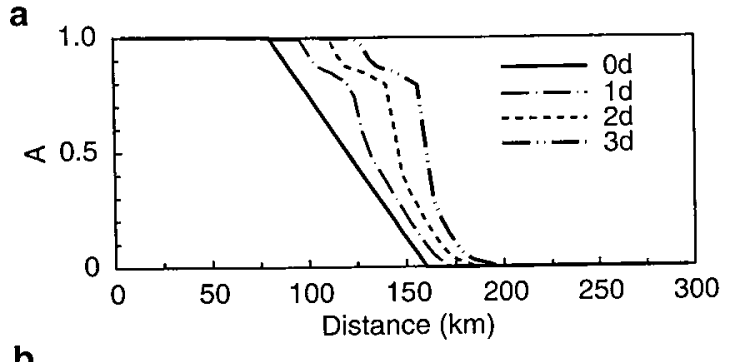

b

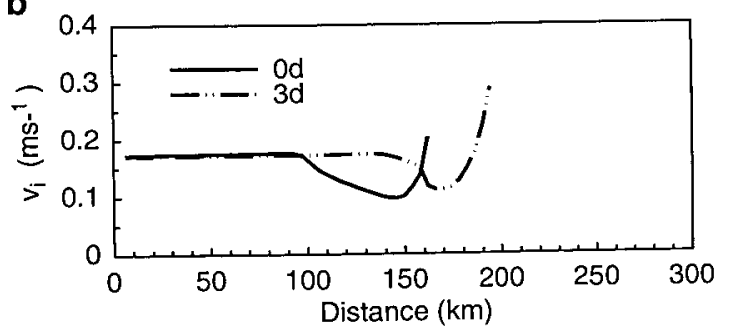

assumed to be at its freezing point of $-1.8^{\circ} \mathrm{C}$. The ice surface temperature is prescribed constant to $-34^{\circ} \mathrm{C}$.

Before the coupled simulation starts, the atmospheric model is run into a quasistationary state using the initial ice distribution. The duration of the coupled simulation is 3 days, which is a typical period for cold-air outbreaks.

In the following, results of five cases are discussed, which differ by the drag parameterization.

Case 1: First, a model run is analysed, where all five drag terms mentioned above are taken into account in the sea ice momentum balance equation. Since the ocean current is neglected, the wind causes the ice to drift with the main component to the current is neglected, the wind causes the west. During the 3 days of simulation, the ice south and a small component to the west. During the 3 days of simulation, the ice distribution within the MIZ changes considerably (Fig. 7.20).

the MIZ, a very sharp gradient of ice concentration a spatially inhomogeneous ice drift The new distribution of ice results from a spatially inhomogeneous ice drift 等 decre north-south gradient of ice concentration in zone, the ice drift is convergent, and the drift velocity this central part of the MIZ increases. In the region with increases strongly with decreasing A. This pattern of sea ice drift can be explained as a result of the various stress terms. The atmospheric drags and the wave radiation 列 stress accelerate the ice drift, whereas the oceanic drags have a decerer since in this study, the ocean current is assumed to be zero. The oceanic form drag increases considerably with decreasing A, except for very small concentrations. The reason is the dependence of form drag on the floe size. It is smaller for an ensemble of larger floes close to the pack ice than for the smaller floes further downstream, an 

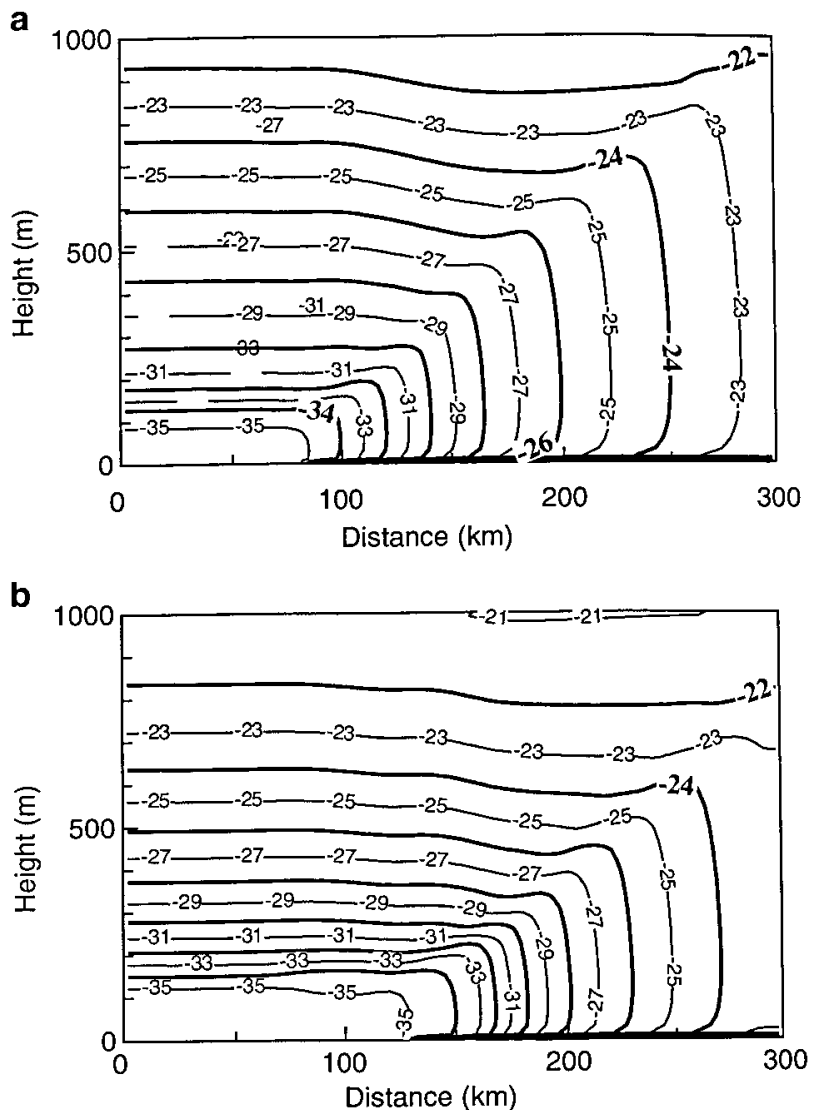

Fig. 7.21 Potential temperature $\left({ }^{\circ} \mathrm{C}\right)$ a in the initial state and $\mathbf{b}$ after 3 days of the coupled simulation as a function of height and distance from the northern (inflow) boundary. The results refer to case 1

effect already described by Steele et al. (1989). Therefore, the larger floes drift with a higher velocity than the smaller floes, and the former collect the smaller floes.

At the southern edge of the MIZ, the strong wave radiation stress and wind stres cause the highest ice drift velocities found in the entire MIZ (Fig. 7.20b). Hence, after 3 days, a zone of more than $10 \mathrm{~km}$ width with very small ice concentration (between 1\% and 5\%) forms the southernmost part of the MIZ.

As evident from Fig. 7.21, the atmospheric flow rapidly adjusts to the changes in the underlying ice cover. Since after 3 days a larger part of the model domain is covered with sea ice than in the beginning, the heat input from the ocean into the atmosphere is reduced. This leads to a considerable decrease of the ABL height over the MIZ, which is after 3 days $200 \mathrm{~m}$ lower at the outflow boundary than in the initial state.
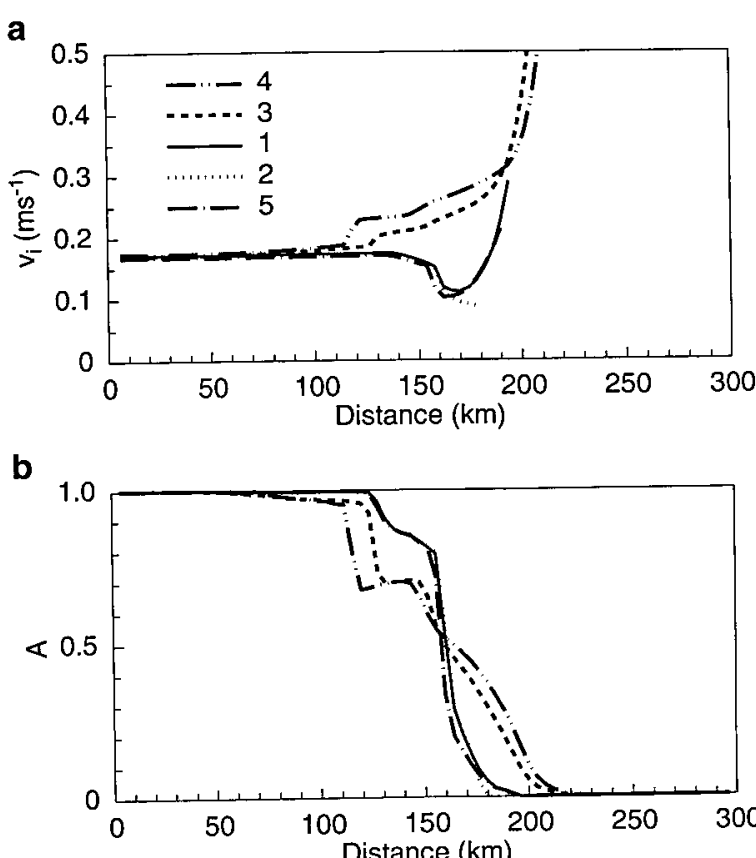

Fig 7.22 (a) Absolute value of ice drift velocity $v$ and (b) ice concentration A after 3 days as a function of distance from the northern (inflow) boundary for case 1 (all stress terms included), case 2 (no radiation stress), case 3 (no form drag), case 4 (no oceanic form drag) and case 5 (no atm. form drag)

Case 2: In this run, the wave radiation stress is neglected. It turns out that in general, Case wave radiation stress has al (1989), who showed with an ice-ocean model that wave radiation stress has only a minor influence on the sea ice drift. However, for very low ice concentrations as at the southern edge of the MIZ, its influence is large. There, the drift velocity is only one third of that in case 1 (see Fig. 7.22).

Case 3: Only wave radiation stress and the frictional forces at the top and the bottom of the ice (skin form drag is neglected. This leads to a considerably different ice drift velocity pattern in the MIZ (Fig. 7.22). The drift velocity increases in the entire region downstream of the pack ice. Furthermore, the ice concentration gradient in the centre of the MIZ is not as pronounced as in case 1.

In case 4 , the oceanic form drag is neglected; in case 5, the atmospheric form drag is neglected.

Comparing all cases, it can be emphasised that besides skin drag, the most important stress is the oceanic form drag, whereas the atmospheric form drag has only a small influence Nevertheless, Birnbaum and Lüpkes (2002) show that its 
influence on the atmospheric fluxes is of large importance. The highest drift velocities occur in case 4 because there only a decelerating stress term, the oceanic form drag, is switched off. The second largest velocities result if, additionally, the accelerative atmospheric form drag is neglected (case 3). Conversely, the drift velocities are generally much lower if the oceanic form drag is taken into account. If only the two skin drags are accounted for, the ice drift velocity is significantly overestimated in most parts of the MIZ. As shown in Fig. 7.22b, after 3 days, the position of the leading edge of the MIZ differs by about $30 \mathrm{~km}$ between case 4 and case 5 .

\section{Summary and Conclusions}

During ACSYS, the ice-atmosphere interaction was studied in the marginal sea ice zone with the coupled ice-atmosphere model METRAS/MESIM. The results demonstrated that the ice drift velocity is very sensitive to the various stress terms. A neglect of oceanic form drag has a strong effect on both the drift velocity and the sea ice distribution in the MIZ.

In this investigation, the ocean current was neglected. Results could be different, especially in case of an accelerating oceanic flow. Furthermore, this analysis was restricted to the relative influence of the different stress terms only for conditions as in the MIZ. Future studies with mesoscale models should also concentrate on the inner Arctic.

\subsection{Stable Boundary Layer Over the Greenland Ice Sheet}

\subsubsection{Simulations of Katabatic Wind Dynamics}

The stable boundary layer (SBL) represents a quasi-permanent phenomenon for most parts of the year over the ice sheets of Greenland and Antarctica. As a result of the slopes of the ice sheets over large areas, katabatic winds develop, and the Coriolis force is important because of the relatively large horizontal scale of the wind system. The katabatic wind system over the sloped ice sheet of Greenland (Fig. 7.23) is very important for the near-surface climate and the air/snow energy and momentum exchange, which in turn plays an important role in questions of the mass balance of the ice sheet. The flow over the interior regions is relatively homogeneous, and hydrostatic mesoscale models with resolutions of $25-40 \mathrm{~km}$ have proven to reproduce the structure of the SBL in good agreement with observations, provided that the vertical resolution of the models is high in the ABL and clouds are forecasted correctly (Klein et al. 2001a; Bromwich et al. 2001). The structure of the katabatic wind system becomes more complex in the coastal areas, where the terrain

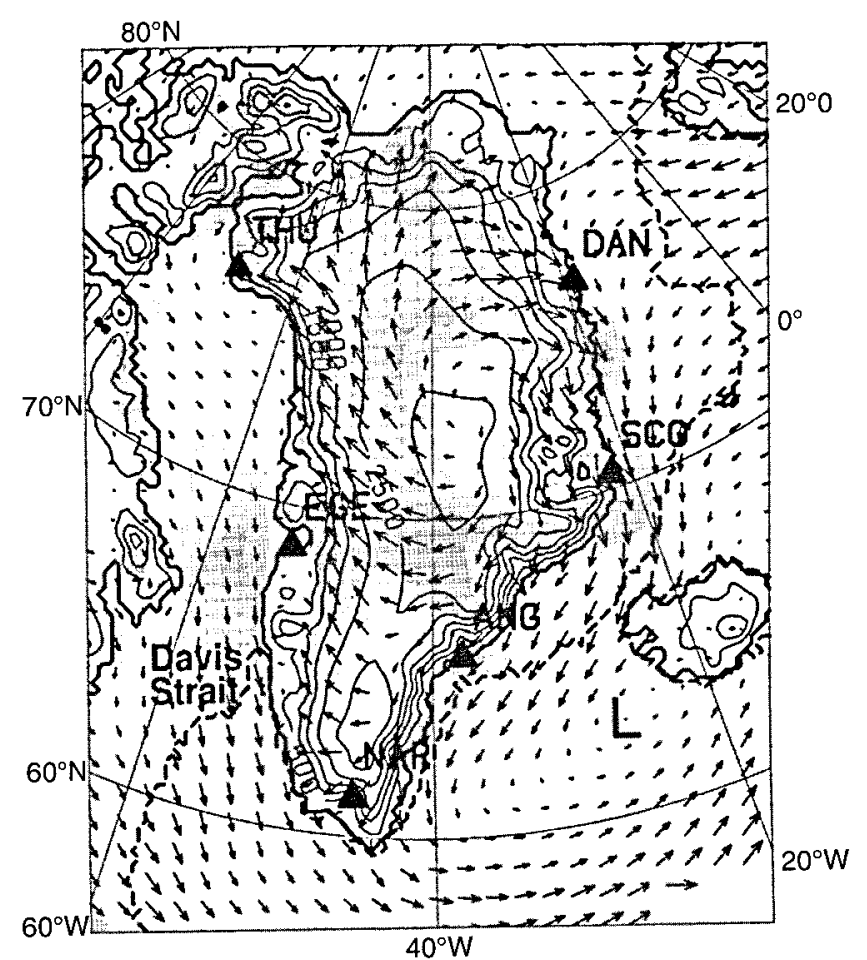

Fig. 7.23 Monthly mean wind field from a simulation with $25 \mathrm{~km}$ resolution for January 1990 ig. 7.23 Mirectional constancy is (only every fouth whe centre of the men represented by shading: light shading $0.8-0.9$, dark she ' $~ L$ '. Greenland radiosonde stations are low-pressure system southwest of Iceland is marked by

is steepest. As a consequence, katabatic winds and associated air/ice interactions are also strongest near the ice margin, and high-resolution, non-hydrostatic models are needed (Klein et al. 2001b). Especially in the transition region between tundra and inland ice along the western coast of Greenland, the surface structures are quite complicated, consisting of steep glaciers, small lakes and fjords with a length scale of a few $\mathrm{km}$.

During the ACSYS decade, our knowledge about the SBL structure over polar ice sheets has increased significantly in both the observational and the modelling point of view. The KABEG experiment (Heinemann 1999) has provided an unprecenter for $3 \mathrm{D}$ structure of mean and turbulent quantities in the katabatic SBL (Heinemann 2002).

The KABEG data set has also been used for a couple of comparisons with mesoscale model simulation studies. As an example, the simulated and observed vertical structure of the SBL is displayed in Fig. 7.24 for a case study on 22 April 
KA3 (22 April 1997):

$\theta(\mathrm{K})$

Location A2 260265270275280285
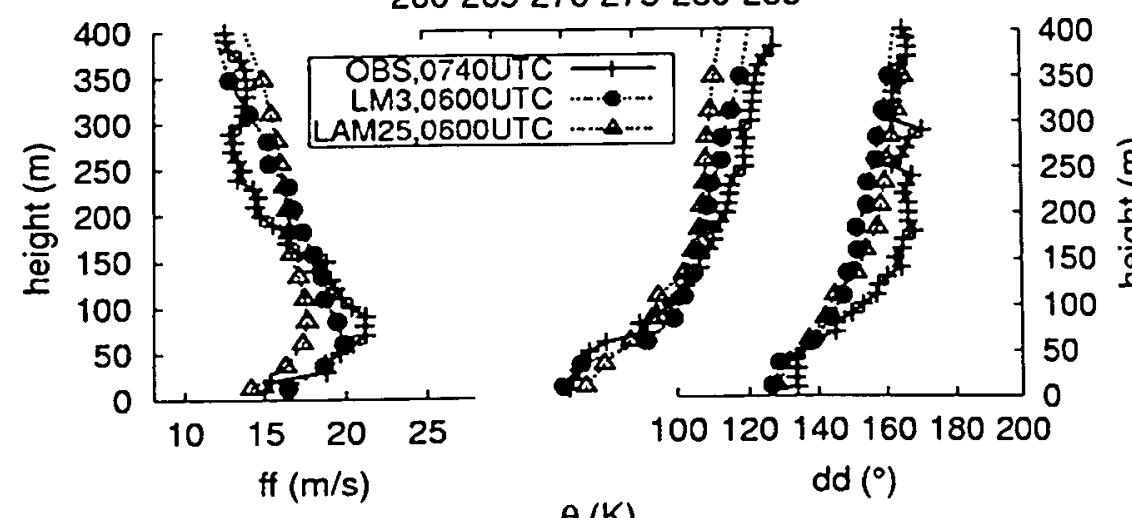

100120140160180200

dd $\left({ }^{\circ}\right)$

$\theta(\mathrm{K})$

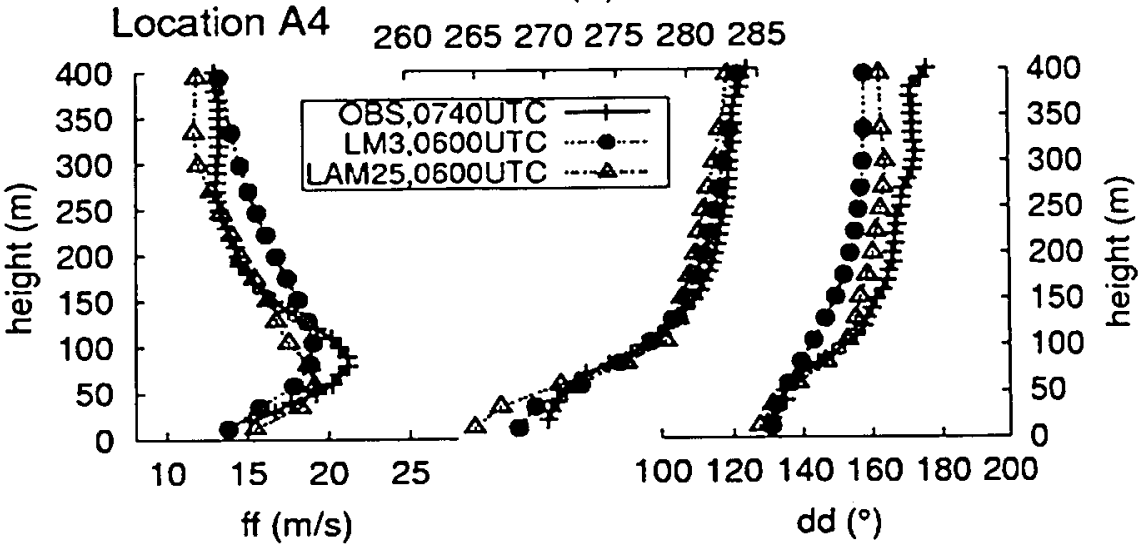

Fig. 7.24 Vertical profiles of observed (full lines with symbols '+'), NORLAM ( $25 \mathrm{~km}$ resolution, $18 \mathrm{~h}$ forecast, full lines with open triangles $)$ and LM $(2.8 \mathrm{~km}$ resolution, $6 \mathrm{~h}$ forecast, full lines with filled circles) simulated wind speed, potential temperature and wind direction at the locations $\mathrm{A}$ (upper panel) and A4 (lower panel) of the KABEG experiment (From Klein et al 2001b, (upper panel) and A4 (lower
www.borntraeger-cramer.de)

1997. Vertical profiles of wind speed, potential temperature and wind direction are shown for two locations over the ice sheet of West Greenland, which coincide with the positions of two surface stations northeast of Kangerlussuaq during KABEG (Klein et al. 2001b). Location A2 has a height of about $800 \mathrm{~m}$ and lies in an area of increased slope near the edge of the ice sheet. Location A4 has a height of about $1,600 \mathrm{~m}$ and is situated at a distance of about $80 \mathrm{~km}$ from the ice edge. The three profiles shown in Fig. 7.24 are the hydrostatic NORLAM simulation with $25 \mathrm{~km}$ resolution, the non-hydrostatic LM simulation with $2.8 \mathrm{~km}$ resolution (both valid at 0600 UTC, 22 April 1997) and measured profiles obtained by KABEG aircraft measurements (at about 0740 UTC). In general, the modelled vertical profiles of both NORLAM and LM agree well with the measured boundary layer profiles, which have been averaged horizontally over $25 \mathrm{~km}$. At site A4, the aircraft data show a well-developed katabatic wind system with a low-level jet (LLJ) of more than $22 \mathrm{~m} / \mathrm{s}$ at a height of about $100 \mathrm{~m}$. The wind speed at heights above $200 \mathrm{~m}$ is relatively high $(13 \mathrm{~m} / \mathrm{s})$, which reflects the strong synoptic forcing for this case. The profile of the potential temperature shows a strong inversion of more than $10 \mathrm{~K}$ per $100 \mathrm{~m}$. The aircraft profiles show a veering of the wind direction with height from $130^{\circ}$ near the surface $\left(40^{\circ}\right.$ right to the local fall line) to southerly directions above the stable boundary layer. The boundary layer structure is captured well by both models, and NORLAM is slightly superior with respect to the wind profile. In the homogeneous area near A4, the higher resolution of the LM has obviously no advantage, and also, the different turbulence schemes of the models (first-order closure in NORLAM, TKE closure in LM) seem to have no major impact on the quality of the simulation of mean quantities. However, at site A2, which is also over the ice but close to the ice margin, the LM results are superior to the NORLAM results since the topography gradient is underestimated in the coarse resolution of NORLAM, and a much weaker LLJ is simulated.

\subsubsection{Interaction Between the Katabatic Wind and the Formation} of Coastal Polynyas

On several occasions, extreme katabatic storms occur when the katabatic wind system is enforced by synoptic processes. A well-known (and feared) phenomenon is the so-called piteraq, which is a strong synoptically enforced katabatic wind at the south-east Greenlandic coast (Fig. 7.23). Near the margins of the Greenland and the Antarctic ice sheet, scale interactions between katabatic storms and other phenomena occur, including the formation of mesocyclones and coastal polynyas. The effect of katabatic storms on the formation of coastal polynyas and polynyas. The effect of been studied by coupling a two-class dynamicassociated feedback processes has been studied by coupling a two-class dynamic-
thermodynamic sea ice model with a mesoscale non-hydrostatic atmospheric model (Heinemann 2003).

As an example of studies with the coupled mesoscale atmospheric/sea ice model with $12 \mathrm{~km}$ resolution, results of idealised studies for the Angmagssalik region of Greenland (near radiosonde station ANG in Fig. 7.23) are given as follows: In the Angmagssalik/Tasiilaq area, several pronounced valleys are presfollows: In the valleys together with the ent and forcing by a cyclone near Iceland leads to the occurrence of extreme synoptic forcing by a cyclone (Klein and Heinemann 2002; Rasmussen 1989). It is also one of the few regions of Greenland where the katabatic wind can extend to the coast. Heinemann (2003) shows that synoptically forced katabatic winds can result in a fast formation of a coastal polynya within $24 \mathrm{~h}$ in that area (Figs. 7.25 and 7.26). For a synoptic forcing of $8 \mathrm{~m} \mathrm{~s}^{-1}$ and north-westerly flow for the 


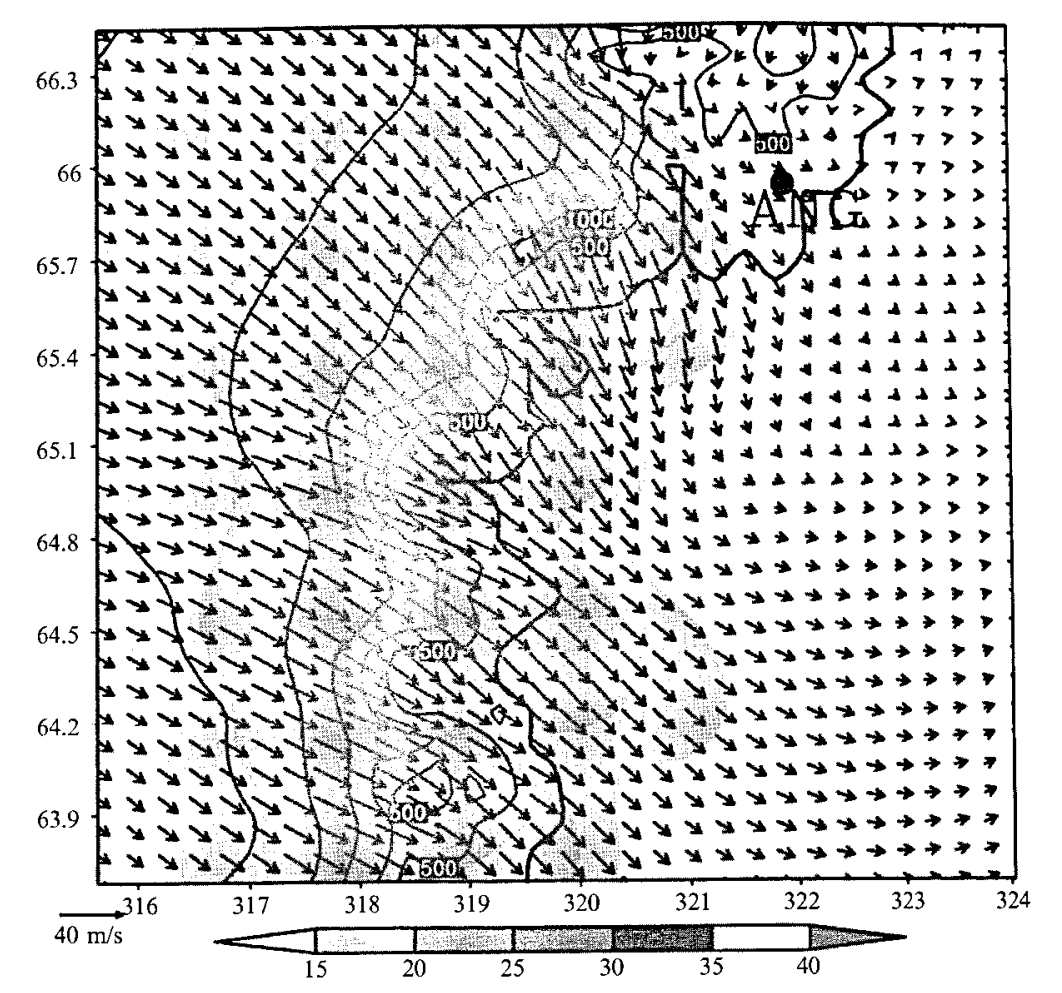

Fig. 7.25 Wind vectors (scale in the lower left) and wind speed (shaded) at $15 \mathrm{~m}$ after $14 \mathrm{~h} \mathrm{simula-}$ tion for a subsection of the 12-km domain of the coupled FOOT3DK/sea ice model (no polynya and $100 \%$ sea ice coverage at the initial stage). The orography is shown as solid isolines every $500 \mathrm{~m}$. The insert in the upper left corner indicates the synoptic forcing (From Heinemann 2003 , Taylor \& Francis Ltd., http://www.tandfonline.com)

Angmagssalik area, which corresponds to the synoptic situation of a stationary synoptic cyclone over Iceland, the near-surface wind field of the $12 \mathrm{~km}$ model after $14 \mathrm{~h}$ simulation (Fig. 7.25) shows the development of a strong synoptically forced katabatic wind in the Angmagssalik area. Maximum near-surface wind speeds are about $30-35 \mathrm{~m} \mathrm{~s}^{-1}$ over the steepest slope areas, and the katabatic wind is channelled by the large valleys. The signal of an orographically generated lee trough can be seen in the sea ice-covered eastern part of the model domain, which supports the extent of the katabatically generated airflow from the ice sheet over the sea ice for relatively larger distances. This large-scale lee trough moves southeastwards during the further development.

The development of a coastal polynya in the Angmagssalik area is displayed by the simulation of the frazil ice coverage in Fig. 7.26. After $6 \mathrm{~h}$ simulation time of the coupled model (not shown), some few isolated areas of frazil ice with $20-40 \%$ concentration (equivalent to a reduction of the consolidated ice

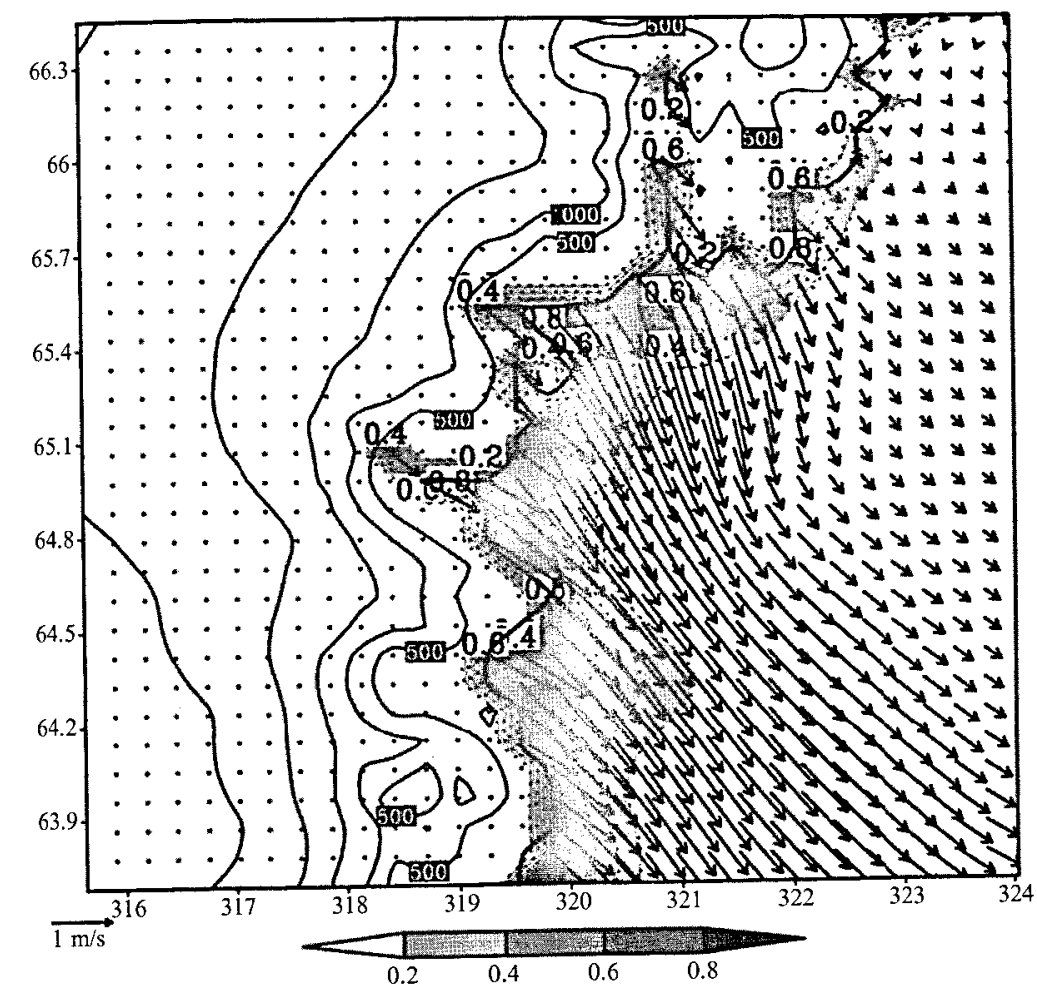

Fig. 7.26 As Fig. 7.25, but for the frazil ice coverage (shaded and dotted isolines every 0.2 ) and ice velocity of the consolidated ice (vector scale in the lower leff), after $22 \mathrm{~h}$ simulation time

of the same amount) have formed at the exit regions of the large valleys. The of the same amount) have formed at the after $22 \mathrm{~h}$ simulation time, extended formation of the polynya proceeds, and after $22 \mathrm{~h}$ simulation the coast. The thinning areas with only $20 \%$ consolidated ice are present near the coast. The thinning of the consolidated ice under the influence of inten Fig. 7.25) results in relatively large ice velocities. Sea ice advection is the frail process during the first $12 \mathrm{~h}$, but the production of frazil ice and the subsequent conversion to consolidated ice become important at later stages. Simulations for a scenario of an eastward-moving cyclone being typical for piteraq events in the Angmagssalik area reproduce the main features known from observational and realistic modelling studies, such as the development of the lee trough, its interaction with the katabatic wind and a development of a low-level mesoscale cyclone in the bay-like area southwest of Angmagssalik. The simulations of the coupled model were performed for the Greenland area, but because of their idealised setup, the results are also applicable for the conditions of the Antarctic. 


\subsection{Summary}

During the ACSYS decade, a lot of studies have been carried out applying mesoscale models aiming at an improved understanding of the most relevant processes in the Arctic boundary layer and their parameterization. The studies addressed many different topics, such as the modelling of cold-air outbreaks, stable on-ice airflows and convective processes caused by leads, clouds and cold-air advection. Furthermore, the impact of ridges and floe edges on surface roughness was investigated. Finally, the interaction of the boundary layer with sea ice was studied in detail during different weather situations such as the passing of mesoscale cyclones. Most studies addressed the boundary layer processes over sea ice. It was shown in the last subsection, however, that also progress has been achieved in the mesoscale modelling of the stable boundary layer over the Greenland ice sheet.

In most of the model runs presented, the initial and boundary conditions were based on observational data obtained from aircraft. Comparison of model results with data mainly focussed on the representation of turbulent fluxes and on the boundary layer structure (thickness and stratification). It was shown that progress has obviously been achieved with the parameterization of fluxes in strong convective situations such as cold-air outbreaks and convection over leads. Remaining uncertainties in the modelling of cold-air outbreaks, which should be subject to future research, concern the role of entrainment and of cloud physical processes for the growth of the convective ABL. A first step was made towards the parameterization of the lead-induced turbulence for high-resolution but non-eddy resolving models. Future work is, however, necessary to derive such parameterizations for climate models.

Based on the modelling of on-ice airflow, it has been concluded that the parameterization of the impact of ridges on surface roughness is of large importance It was shown that ridges influence the wind and temperature distribution not only close to the surface but also in the entire ABL. Progress has been made with the parameterization of the near-surface fluxes modified by ridges and by ice floe edges. In case of floes of up to $1 \mathrm{~km}$ width, the drag coefficients can be parameterized according to Lüpkes and Birnbaum (2005) as a function of sea ice concentration. However, in the inner Arctic regions with complete sea ice cover, the drag parameterizations require the knowledge of the surface topography. This forms a large challenge for remote sensing since the present resolution of satellite sensors is not high enough for the detection of small ridges.

One of the studies considered the effects of several factors acting simultaneously on the flow over a region covered almost completely with sea ice. It was shown that the surface layer stratification was influenced mainly by downward longwave radiation from clouds, upward heat fluxes from leads and cold-air advection. The latter produced upward fluxes over the sea ice, which was not often described in the literature for wintertime conditions.

The influence of atmospheric forcing and sea ice distribution on sea ice export through Fram Strait has been investigated during the ACSYS period with the coupled atmosphere-sea ice model METRAS/MESIM. The model results have shown that mesoscale heterogeneities in atmospheric forcing and sea ice cover can considerably change the sea ice export.

Another study with the same model system demonstrated that in the MIZ, the ice drift velocity is very sensitive to the various stress terms. A neglection of oceanic form drag has at least in the MIZ a considerable effect on both the drift velocity and the sea ice distribution. Future studies should investigate the role of the different stress terms also in the more inner Arctic regions with larger floes and a larger impact of ridges than floe edges.

Fortunately, it was shown that the hydrostatic assumption works reasonably well in mesoscale models not only for the stably stratified boundary layer over sea ice but also for cases with shallow convection over leads. Parameterizations of the energy and momentum fluxes in the ABL or the correct treatment of clouds seem to have a larger impact on the results compared with the effect of the hydrostatic assumption. Application of a higher horizontal and vertical resolution would most probably improve the performance of climate models in the Arctic, which are in most cases hydrostatic ones.

Although many different topics were addressed by the mesoscale modelling and observational studies during ACSYS, there are still many open questions to be addressed in future programmes. It is beyond the scope of the present chapter to develop a complete future strategy of mesoscale research. But a few points can be addressed here.

Most of the studies carried out during ACSYS were focussing on the ice edge zones and considered processes during winter and spring. As already mentioned, future studies should include the inner pack-ice regions and also summer conditions in both the MIZ and the central Arctic. This seems to be important also in the light of the dramatic changes, which occurred in the years after ACSYS such as the strong sea ice melting in summer 2007. Promising activities are the use of data from drifting stations and campaigns focussing on the melting processes of sea ice. Recent publications have demonstrated that a better understanding of the Arctic cocosses above the ABL and climate processes also requires processes. Furthermore, observations used for modeltheir interaction with ABL processes. Furthermore, observations used for model-
ling studies during ACSYS were mostly carried out under fair weather conditions. So, finally, more attempts should be made in the future to include observations during severe weather conditions, when the turbulent fluxes of energy and momentum ing severe weather conditions, when the turbulent upper layers.

perman Acknowledgements Part of the presented research was conducted in the frame of the German ACSYS joint programme funded by the Federal Ministry of Education and Research (FKZ 03PL034A and FKZ 03PL034C). Other parts were funded by the Deutsche Forschungsgemeinschaft under grants $\mathrm{He}$ 2740/1 and WA 1334/2-1 and within SFB512. The project ARTIST was funded by the EU (grant no. ENV4-CT97-0487). Finalisation of this work was supported by the EC 6th Framework Programme DAMOCLES. The model simulations were performed on the DKRZ computers within Pre University of Hamburg contingent. KABEG was an experiment of the Meteorologisches Institu (he Alfred-Wegener-Institut (AWI). The ECMWF 
provided the analyses taken as initial and boundary conditions for simulations presented in Sects. 7.3 and 7.6. SSM/I data used for the derivation of the sea ice coverage for KABEG and ARTIST were provided by the Global Hydrology Resource Center (GHRC) at the Global Hydrology and Climate Center (Huntsville, Alabama, USA).

The numerical models were provided by the Institut für Geophysik und Meteorologie Universität zu Köln, the Norwegian Meteorological Institute (DNMI, Oslo), the German Meteorological Service (DWD, Offenbach) and the University of Hamburg.

\section{References}

Affeld B (2003) Zyklonen in der Arktis und ihre Bedeutung für den Eistransport durch die Framstraße. Dissertation, FB Geowissenschaften, Universität Hamburg

Alam A Curry JA (1997) Determination of surface turbulent fluxes over leads in Arctic sea ice. J Geophys Res 102:3331-3344

Alestalo M, Savijärvi H (1985) Mesoscale circulations in a hydrostatic model: coastal convergence and orographic lifting. Tellus 37A:156-162

Anderson RJ (1987) Wind stress measurements over rough sea ice during the 1984 marginal ice zone experiment. J Geophys Res 92(C7):6933-6941

Andreas EL, Cash BA (1999) Convective heat transfer over wintertime leads and polynyas. J Geophys Res 104(C11):25721-25734

Andreas EL, Paulson CA, Williams RM, Lindsay RW, Businger JA (1979) The turbulent heat flux from Arctic leads. Boundary Layer Meteorol 17:57-91

Andreas EL, Tucker WB, Ackley SF (1984) Atmospheric boundary-layer modification, drag coefficient, and surface heat flux in the Antarctic marginal ice zone. J Geophys Res 89(NCl): 649-661

Atkinson BW, Zhang JW (1996) Mesoscale shallow convection in the atmosphere. Rev Geophys 34:403-432

Augstein E, Lüpkes C, Hartmann J (2000) Atmospheric boundary layer investigations over the Arctic Ocean, in: Final Report on The Arctic Radiation and Turbulence Interaction Stud (ARTIST), Contract Nr. ENV4-CT97-0497-0487 (DG12-ESCY), Bremerhaven, pp 5-21

Bange J, Buschmann M, Spiess T, Zittel, Vorsmann P (2002) Umrüstung der Hubschrauberschleppsonde Helipod, Vorstellung eines einzigartigen meteorologischen Forschungssystems. Deutscher Luft- und Raumfahrtkongress, Stuttgart, 23-26 Sept 2002

Birnbaum G (1998) Numerical modelling of the interaction between atmosphere and sea ice in the Arctic marginal sea ice zone. Reports on polar research, vol 268. Alfred Wegener Institute, Bremerhaven

Birnbaum G, Lüpkes C (2002) A new parameterization of the surface drag in the marginal sea ice zone. Tellus 54A:107-123

Bromwich DH, Cassano JJ, Klein T, Heinemann G, Hines KM, Steffen K, Box JE (2001) Mesoscale modeling of katabatic winds over Greenland with polar MM5. Mon Weather Rev $129: 2290-2309$

Brümmer B (1996) Boundary-layer modification in wintertime cold-air outbreaks from the Arctic sea ice. Boundary Layer Meteorol 80:109-125

Brümmer B (1997) Boundary-layer mass, water, and heat budgets in wintertime cold-air outbreaks from the Arctic sea ice. Mon Weather Rev 125:1824-1837

Brümmer B (1999) Roll and cell convection in wintertime Arctic cold-air outbreaks. J Atmos Sci 56:2613-2636

Brümmer B, Höber H (1999) A mesoscale cyclone over the Fram Strait and its effect on sea ice. J Geophys Res 104(D16): 19085-19098

Brümmer B, Thiemann S (2002) The atmospheric boundary layer in an Arctic wintertime on-ice air flow. Boundary Layer Meteorol 104:53-72
Brümmer B, Rump B, Kruspe G (1992) A cold air outbreak near Spitsbergen in springtime boundary-layer modification and cloud development. Boundary Layer Meteorol 61:13-46

Brümmer B, Busack B, Hoeber H (1994) Boundary-layer observations over water and Arctic sea ice during on-ice air flow. Boundary Layer Meteorol 68:75-108

Chen $B$, Vihma T (2002) Modelling of sea ice thermodynamics during warm-air advection. J Glaciol 48:425-438

Chlond A (1992) Three-dimensional simulation of cloud street development during a cold air outbreak. Boundary Layer Meteorol 58:161-200

Chrobok G, Raasch S, Etling D (1992) A comparison of local and nonlocal turbulence closure methods for the case of a cold air outbreak. Boundary Layer Meteorol 58:69-90

Claussen M (1991) Local advection processes in the surface layer of the marginal ice zone. Boundary Layer Meteorol 54:1-27

Dare RA, Atkinson BW (1999) Numerical modelling of atmospheric response to polynyas in the Southern Ocean sea ice zone. J Geophys Res 104(D14):16691-16708

Dare RA, Atkinson BW (2000) Atmospheric response to spatial variations in concentration and size of polynyas in the Southern Ocean sea-ice zone. Boundary Layer Meteorol 94:65-88

ire $\mathrm{S}$, Schlünzen $\mathrm{KH}(2005)$ Influence parameters for a polar mesocyclone development. Meteorol Z 14:781-792

- Miü S. Siüler G (2005) Atmosphere-sea ice interactions during a cyclone passage investigated by using model simulations and measurements. Mon Weather Rev 133(12):3678-3692

Doms G, Schättler U (2002) A description of the nonhydrostatic regional model LM. Part I:

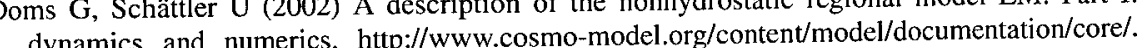
Accessed 10 Mar 2010

Etling D, Brown RA (1993) Roll vortices in the planetary boundary layer: a review. Boundary Layer Meteorol 65:215-248

Fairall CW, Markson R (1987) Mesoscale variations in surface stress, heat fluxes, and drag coefficient in the marginal ice zone during the 1983 marginal ice zone experiment. J Geophys Res 92:6921-6932

Gallee $H$ (1997) Air-sea interactions over Terra Nova Bay during winter: simulation with a coupled atmosphere-polynya model. J Geophys Res 102:13835-13849

coupled a a low-level air flow. J Geophys Res 104(D20):24499-24507

flow. J Gephys Res 104(D20):24 Joff $M$ (2002) Atmospheric drag coeficients over sea ice validation of a parameterization concept. Tellus 54A:205-219

validation of a parameterization concept. Tellus 54A:205-219 Glendening JW (1994) Dependence of boundary layer structure

upon geostrophic wind direction. J Geophys Res 99.5569-5581 Glendening JW, Burk SD (1992) Turbulent transport from an Arctic lead: a large eddy simulation. Boundary Layer Meteorol 59:315-339

Gryschka M, Raasch S (2005) Roll convection during a cold air outbreak: a large eddy simulation with stationary model domain. Geophys Res Lett 32:L14805. doi:10.1029/2005GL022872

Guest PS, Davidson KL (1987) The effect of observed ice conditions on the drag coefficient in the summer East Greenland marginal sea ice zone. J Geophys Res 92(C7):6943-6954

su Guest PS, Gling

. Hartmann J, Kotmeier, Wan 105 . Alfred Wegener Institute, Bremerhaven

Reports on Polar Research, vol $\mathrm{C}$. All) Roll vortices and boundary layer development during Hartmann J, Kottmeier C, Raasch S (1997) Roll vortices and

a cold air outbreak. Boundary Layer Meteorol $84.45-46$ (n) Hartmann J, Albers F, Argentini S et al (1999) Arctic Radiation and Turbulence Intemerhaven

(ARTIST). Reports on Polar Research, vol 305. Alfed Wegent inster, Brite Hehl O (1997) Die Bestimmung der hydrodynamischen Rauhgkeil dor Unerseite polaren Meereises - Numerische Simulationen. Berichte des Institutes fur Hannover Klimatologie der Universität Hannover, vol 52. University of Hannover, Hannover 
Heinemann G (1999) The KABEG'97 field experiment: an aircraft-based study of the katabatic wind dynamics over the Greenlandic ice sheet. Boundary Layer Meteorol 93:75-116

Heinemann G (2002) Aircraft-based measurements of turbulence structures in the katabatic flow over Greenland. Boundary Layer Meteorol 103:49-81

Heinemann $\mathrm{G}$ (2003) Forcing and feedback mechanisms between the katabatic wind and sea ice in the coastal areas of polar ice sheets. Glob Atmosphere-Ocean Sys 9:169-201

Heinemann G, Klein T (2002) Modelling and observations of the katabatic flow dynamics over Greenland. Tellus 54A:542-554

Hibler WD III (1979) A dynamic thermodynamic sea ice model. J Phys Oceanogr 9(4):815-846

Inoue J, Kosovic B, Curry JA (2005) Evolution of a storm-driven cloudy boundary-layer in the Arctic. Boundary Layer Meteorol 117:213-230

Intrieri JM, Fairall CW, Shupe MD, Persson POG, Andreas EL, Guest PS, Moritz RE (2002) An annual cycle of Arctic surface cloud forcing at SHEBA. J Geophys Res. doi: $10.1029 / 2000$ JC000439

Kaleschke L, Lüpkes C, Vihma T, Haarpaintner J, Bochert A, Hartmann J, Heygster G (2001) SSM/I sea ice remote sensing for mesoscale ocean-atmosphere interaction analysis. Can J Remote Sens 27(5):526-537

Kantha LH, Mellor GL (1989) A numerical model of the atmospheric boundary layer over a marginal ice zone. J Geophys Res 94:4959-4970

Kessler $E$ (1969) On the distribution and continuity of water substance in atmospheric circulations. Metrol Monogr 32:1-84

Klein T, Heinemann $G$ (2002) Interaction of katabatic winds and mesocyclones at the eastern coas of Greenland. Meteorol Appl 9:407-422

Klein T, Heinemann G, Bromwich DH, Cassano JJ, Hines KM (2001a) Mesoscale modeling of katabatic winds over Greenland and comparisons with AWS and aircraft data. Meteorol Atmos Phys 78:115-132

Klein T, Heinemann G, Gross P (2001b) Simulation of the katabatic flow near the Greenland ice margin using a high-resolution nonhydrostatic model. Meteorol Z (NF) 10:331-339

Kottmeier C, Hartmann J, Wamser C, Bochert A, Lüpkes C, Freese D, Cohrs W (1994) Radiation and Eddy Flux Experiment 1993 (REFLEX II), Reports on polar research, vol 133. Alfred Wegener Institute for Polar and Marine Research, Bremerhaven

Kreyscher M, Harder M, Lemke P, Flato GM (2000) Results of the sea ice model intercomparison project: evaluation of sea-ice rheology schemes for use in climate simulations. J Geophys Res 105:11299-11320

Lemke P, Owens WB, Hibler WD III (1990) A coupled sea ice-mixed layer-pycnocline model for the Weddell Sea. J Geophys Res 95:9513-9525

Liu AQ, Moore GWK, Tsuboki K, Renfrew IA (2004) A high-resolution simulation of convective roll clouds during a cold-air outbreak. Geophys Res Lett 31:L03101. doi:10.1029/2003GL 018530

Lüpkes C, Birnbaum G (2005) Surface drag in the arctic marginal sea ice zone - a comparison of different parameterisation concepts. Boundary Layer Meteorol 117:179-211

Lüpkes C, Gryanik VM (2005) The effect of sea ice on regional atmospheric processes in the Arctic, in Final report ACSYS, coordinated by A. Hense, Grant 03 PL034, Universität Bonn, Bonn, pp 11-21

Lüpkes C, Schlünzen KH (1996) Modelling the arctic convective boundary-layer with differen turbulence parameterisation. Boundary Layer Meteorol 79:107-130

Lüpkes C, Hartmann J, Birnbaum G et al. (2004) Convection over Arctic leads (COAL). In: Schauer U, Kattner G. (ed) The expedition ARKTIS XIX a,b and XIX/2 of the Research Vessel 'Polarstern' in 2003. Reports on Polar Research, vol 481. Alfred Wegener Institute for Polar and Marine Research, Bremerhaven, pp 47-62

Lüpkes C, Gryanik VM, Witha B, Gryschka M, Raasch S, Gollnik T (2008) Modelling convection over leads with LES and a non-eddy-resolving microscale model. J Geophys Res C09028. doi: 10.1029/2007JC004099

Lynch AH, Chapman WL, Walsh JE, Weller G (1995) Development of a regional climate model of the western Arctic. J Clim 8:1555-1570
Mai S (1995) Beziehungen zwischen geometrischer und aerodynamischer Oberflächenrauhigkeit arktischer Meereisflächen. M.S. thesis, University of Bremen

Mai S, Wamser C Kotmeier C (1996) Geometric and aerodynamic roughness of sea ice. Boundary Layer Meteorol 77:233-248

Makshtas AP (1991) The heat budget of Arctic ice in the winter. International Glaciological Society, Cambridge

Mauritsen T, Svensson G, Grisogono B (2005) Wave flow simulations over arctic leads. Boundary Layer Meteorol 117:259-273

McPhee MG (1979) The effect of the oceanic boundary layer on the mean drift of pack ice: application of a simple model. J Phys Oceanogr 9:388-400

Müller G, Brümmer B, Alpers W (1999) Roll convection within an Arctic cold-air outbreak: interpretation of in situ aircraft measurements and spaceborne SAR imagery by a threedimensional atmospheric model. Mon Weather Rev 127(3):363-380

Dison PQ, Harrington JY (2000) Dynamics and energetics of the cloudy boundary layer in simulations of off-ice flow in the marginal ice zone. J Geophys Res 105(D9):11889-11899

Overand JE (1985) Atmospheric boundary layer structure and drag coefficients over sea ice. J Geophys Res 90:9029-9049

Overland JE, Guest PS (1991) The Arctic snow and air temperature budget over sea ice during winter. J Geophys Res $96: 4651-4662$

worki M, Moore GWK (2001) A numerical study of an extreme cold-air outbreak over the

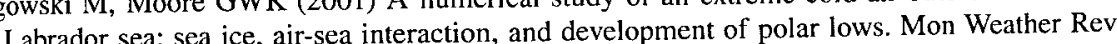
129(2):47-72

Paulson CA, Smith JD (1974) The AIDJEX lead experiment. AIDJEX Bull 23:1-8

Perrie W, Hu Y (1997) Air-ice-ocean momentum exchange. Part II: ice drift. J Phys Oceanogr 27:1976-1996

Person POG, Ruffieux D, Fairall CW (1997) Recalculations of pack ice and lead surface energy budgets during the Arctic leads experiment (LEADEX) 1992. J Geophys Res 102 : 25085-25089

Persog POG, Firall Andreas EL Guest PS, Perovich DK (2002) Measurements near the atmo. spheric surface flux group tower at 1029/2000JC000705

J Geophys Res 107.8045. doi.10.1029/2000J Pinto JO (1998) Autumnal mixed-phase cloudy boundary layers 2016-2038

Pinto JO, Alam A, Maslanik JA, Curry JA, Stone RS (2003) Surface characteristics an atmospheric footprint of springtime Arctic leads at SHEBA. J Geophys Res 108:8051. doi:10.1029/2000JC000473

Raasch S (1990) Numerical simulation of the development of the convective boundary layer during a cold air outbreak, Boundary Layer Meteorol 52:349-375

a ch S Schröter M (2001) PALM - a large eddy simulation model performing on massively Rarallel computers. Z Meteorol 10:363-372

Rarallesten blaeste $i$ havet. Vejre, 2, Danish Meteorological Society, pp 3-14

Meteorological Society, RuffieuX D, Persson POG, Fairall CW, Res 100:4593-4612

during LEADEX 1992. J Geophys Res 100.459 ) Flow over small heat islands: a numerical sensitivity study. Savijärvi $\mathrm{H}$, Matthews $\mathrm{S}(2007$
J Atmos Sci $61: 859-868$

U. (her 'Polarstern' in 2003. Reports on Po
and Marine Research, Bremerhaven

Schlinzen KH (1990) Numerical studies on the in-land penetration of sea breeze fronts at coastline with tidally flooded mudflats. Beitr Phys Atmos 63:243-256

(2003) Relevance of sub-grid-scale land-use effects for mesoscal models. Tellus 55A:232-246 
Schlünzen KH, Bigalke, K, Lüpkes, C, Niemeier U, v. Salzen K (1996) Concept and realization of the mesoscale transport and fluid model ,METRAS'. Technical Report 5, METRAS, Meteorologisches Institut, Universität Hamburg

Schnell RC, Barry RG, Miles MW, Andreas EL, Radke LF, Brock CA, McCormick MP, Moore JL (1989) Lidar detection of leads in Arctic sea ice. Nature 339:530-532

Serreze MC, Maslanik JA, Rehder MC, Schnell RC, Kahl JD, Andreas EL (1992a) Theoretical heights of buoyant convection above open leads in the winter Arctic pack ice cover. J Geophys Res 97:941I-9422

Serreze MC, Kahl JD, Schnell RC (1992b) Low-level temperature inversions of the Eurasian Arctic and comparisons with Soviet drifting station data. J Clim 5:615-629

Smith SD, Anderson RJ, den Hartog G, Topham DR, Perkin RG (1983) An investigation of a polynya in the Canadian Archipelago 2, structure of turbulence and sensible heat flux. J Geophys Res 88:2900-2910

Steele M, Morison JH, Untersteiner N (1989) The partition of air-ice-ocean momentum exchange as a function of ice concentration, floe size, and draft. J Geophys Res 94:12739-12750

Tjernström M, Zagar M, Svensson G, Cassano JJ, Pfeifer S, Rinke A, Wyser K, Dethloff K, Jones C, Semmler T, Shaw M (2005) Modelling of the Arctic boundary layer: an evaluation of six ARCMIP regional-scale models using data from the SHEBA project. Boundary Layer Meteorol 117:337-381

Troen IB, Mahrt L (1986) A simple model of the atmospheric boundary-laver: sensitivity to surface evaporation. Boundary Layer Meteorol 37:129-148

Vihma T (1995) Subgrid parameterization of surface heat and momentum fluxes over polar oceans. J Geophys Res 100:22625-22646

Vihma T, Briummer B (2002) Observations and modelling of on-ice and off-ice air flows over the northern Baltic Sea. Boundary Layer Meteorol 103:1-27

Vihma T, Pirazzini R (2005) On the factors controlling the snow surface and 2-m air temperatures over the Arctic sea ice in winter. Boundary Layer Meteorol 117:73-90

Vihma T, Hartmann J, Lüpkes C (2003) A case study of an on-ice air flow over the Arctic marginal sea ice zone. Boundary Layer Meteorol 107:189-217

Vihma T, Lüpkes C, Hartmann J, Savijärvi H (2005) Observations and modelling of cold-air advection over Arctic sea ice. Boundary Layer Meteorol 117(2):275-300

von Salzen K, Claussen M, Schlünzen KH (1996) Application of the concept of blending height to the calculation of surface fluxes in a mesoscale model. Meteorol Z 5(2):60-66

Wacker U, Potty KVJ, Lüpkes C, Hartmann J, Raschendorfer M (2005) A case study on a polar cold air outbreak over Fram Strait using a mesoscale weather prediction model. Boundary Layer Meteorol 117(2):301-336

Wang S, Wang Q, Jordan RE, Persson POG (2001) Interactions among longwave radiation of clouds, turbulence, and snow surface temperature in the Arctic: a model sensitivity study. J Geophys Res 106:15323-15333

Wefelmeier C (1992) Numerische Simulation mesoskaliger, dynamischer Wechselwirkungen zwischen Atmosphäre, Eis und Ozean, vol 42. Berichte des Instituts für Meteorologie un Klimatologie der Universität Hannover

Wefelmeier C, Etling D (1991) The influence of sea ice distribution on the atmospheric boundary layer. Z Meteorol 41(5):333-342

Weinbrecht S, Raasch S (2001) High-resolution simulations of the turbulent flow in the vicinity of an Arctic lead. J Geophys Res 106(C11):27035-27046

Zulauf MA, Krueger SK (2003) Two-dimensional cloud-resolving modelling of the atmospheric effects of Arctic leads based upon midwinter conditions at the surface heat budget of the Arctic ocean ice camp. J Geophys Res 108(D10):4312. doi: 10.1029/2002JD002643

\section{Chapter 8 \\ Arctic Regional Climate Models}

K. Dethloff, A. Rinke, A. Lynch, W. Dorn, S. Saha, and D. Handorf

Abstract In this chapter, we provide an overview of current applications of regional limate mode (RCMs) to the Arctic. There are increased applications of RCMs to present-day climate simulations and process parameterisations. Any advances in regional climate modelling must be based on analysis of physical processes in comparison with observations. In data-poor regions like the Arctic, this approach may be completed by a collaborative analysis of several research groups. Within the ARCMIP (Arctic Regional Climate Model Intercomparison Project), simulations for the SHEBA year 1997-1998 have been performed by several Arctic RCMs. The us of contribute to a better description of important regional physical processes in the ocean, cryosphere, atmosphere, land and biorems in coupled regional model systems. This is based on identifying and modelling of the key processes and on an assessment of the improved understanding in the light of analysis of instrumental as well as paleocliimproved understanding in the light of anal The main goal is to address the deficiencies matic and paleoenvironmental records. The main goal is to address the deficiencies in understanding the Arctic by developing improved physical descriptions of Arctic
climate feedbacks in atmospheric and coupled regional climate models and to

K. Dethloff $(\otimes) \cdot$ A. Rinke $\bullet$ W. Dorn $\bullet$ D. Handorf

Alfred Wegener Institute for Polar and Marine Research, Research Unit Potsdam, Telegrafenberg A43, D-14473 Potsdam, Germany

e-mail: Klaus.Dethloff@awi.de; Annette.Rinke@awi.de; Wolfgang.Dorn@awi.de; Doerthe.Handorf@awi.de

A. Lynch

School of Geography and Environmental Sciences, Monash University,

Melbourne, VIC 3800, Australia

e-mail: Amanda.Lynch@arts.monash.edu.au

S. Saha

C

e-mail: Subodh@tropmet.res.in

The ACSYS Decade

P. Leme and Atmospheric (eds.), Arctic Climate Change. The ACSYS

and Beyond, Atmospheric and Oceanographic Sciences Library 43, 